Dejando atrás el discurso de la «grieta». ¿Cómo aumentar la confianza entre los argentinos?

José Eduardo Jorge, Gabriel Alberto Lamanna, Mara Leguizamón y Ulises Steciow

DOI: https://doi.org/10.24215/16696581e262

\title{
Dejando atrás el discurso de la «grieta». ¿Cómo aumentar la confianza entre los argentinos?
}

\section{Leaving the discourse on the «crack» behind. How to increase trust among Argentines?}

José Eduardo Jorge jiorge@perio.unlp.edu.ar http://orcid.org/0000-0003-3596-1285

Facultad de Periodismo y Comunicación Social; Universidad Nacional de La Plata, Argentina

Gabriel Alberto Lamanna liclamanna@gmail.com

Facultad de Periodismo y Comunicación Social; Universidad Nacional de La Plata, Argentina

Mara Leguizamón mara.leguizamon@gmail.com

Universidad Nacional de La Plata, Argentina

Ulises Steciow steciowulises@gmail.com

Universidad Nacional de La Plata, Argentina 
José Eduardo Jorge, Gabriel Alberto Lamanna, Mara Leguizamón y Ulises Steciow Dejando atrás el discurso de la «grieta». ¿Cómo aumentar la confianza entre los argentinos?

\section{Resumen}

Tras discutir las razones de la narrativa de la grieta y la fuente de potenciales tensiones sociales y políticas que el actual modelo de globalización representa hoy para democracias como la Argentina, el artículo examina las principales líneas de investigación sobre la naturaleza, causas y efectos de la confianza social y política. A partir de datos de World Values Survey (WVS) y Latinobarómetro, se analizan los dos tipos de confianza entre los argentinos en perspectiva comparada internacional y su evolución en las últimas dos décadas. Con una batería de modelos de regresión que predicen distintas formas de confianza social en la sociedad argentina, se proponen lineamientos generales de política pública. Un desarrollo equilibrado, con políticas universales que promuevan la igualdad; un sistema institucional y un aparato estatal imparciales, efectivos y transparentes, que sancionen las conductas no cooperativas, y dirigentes que respondan a las demandas de la población, son las vías para elevar gradualmente la confianza social y política y romper los círculos viciosos que las han mantenido deprimidas durante décadas.

Palabras Clave: confianza social; confianza política; cultura política.

\section{Abstract}

After discussing the reasons for the narrative on the crack and the source of potential social and political tensions that the current globalization model represents today for democracies such as Argentina, the article examines the main lines of research on the nature, causes and effects of social and political trust. Based on data from the World Values Survey (WVS) and Latinobarómetro, the work analyzes the two types of trust among Argentines in an international comparative perspective and their evolution over the past two decades. Using a battery of regression models that predict different forms of social trust in Argentine society, general public policy guidelines are proposed. A balanced development, with universalistic policies that promote equality; an impartial, effective and transparent institutional system and state apparatus that sanction non-cooperative behaviors, and responsive political leaders, are ways to gradually raise social and political trust and break the vicious circles that have kept them depressed for decades.

Keywords: social trust; political trust; political culture. 
La idea de una sociedad dividida e incapaz de alcanzar consensos políticos básicos ha sido una referencia constante del discurso público argentino de los últimos años. Por su uso generalizado, el término grieta vino a condensar ambiguamente las más variadas opiniones sobre la naturaleza de esa supuesta escisión. Las discusiones en los medios suelen asumir que "la grieta" reside en la sociedad y emana de ella hacia el sistema político, creando proyectos inconciliables de país.

La evidencia empírica no parece respaldar los supuestos de un debate que se ha basado en argumentos impresionistas. Analizando la evolución de las actitudes de los argentinos desde la recuperación de la democracia en un conjunto de cuestiones económicas y culturales clave, uno de nosotros no halló tendencias significativas a la polarización, tanto en el nivel de la sociedad como en grupos específicos (Jorge, 2018a).

En este artículo abordamos el problema desde una perspectiva distinta, preguntándonos cuáles son las vías para promover la confianza social y política entre los argentinos. Apoyándonos en las principales líneas de investigación sobre el tema y en un conjunto de análisis a partir de datos de World Values Survey (WVS) y Latinobarómetro, proponemos lineamientos generales de política pública para aumentar ambos tipos de confianza.

\section{La grieta: discurso y realidad}

Muchos comentaristas asumen que las aparentes tendencias -no siempre cristalizadas- a la llamada polarización del voto son evidencia de una grieta entre los argentinos. Pero la concentración del sufragio en dos opciones no permite afirmar que la sociedad misma esté dividida (Fiorina y Abrams, 2008, pp. 574-5). Como los votantes deciden comparando sus propias posiciones políticas con las de los candidatos, no es posible inferir sus posiciones conociendo solo su decisión (el voto). De haber candidatos con otras ideas y propuestas, el electorado podría repartirse de otro modo. La distribución de las evaluaciones positivas y negativas que hace el público de las figuras políticas -en especial, las polarizantes- está sujeta a la misma lógica.

El uso del término grieta se ha extendido a cualquier diferencia de opinión, valores o intereses, de un modo poco compatible con el pluralismo democrático. Además, no toda diferencia hace difícil el consenso. Para que esto ocurra, las posiciones de las partes deben moverse hacia los extremos y alejarse entre sí (Jorge, 2018ª , pp. 11-13). No basta que la opinión se reparta en 
José Eduardo Jorge, Gabriel Alberto Lamanna, Mara Leguizamón y Ulises Steciow Dejando atrás el discurso de la «grieta». ¿Cómo aumentar la confianza entre los argentinos?

dos opciones para hablar de polarización. Ésta es función además del extremismo y la distancia de las posiciones.

Varios factores pueden hacer que periodistas y público perciban una fractura en la comunidad política. En muchas democracias gobierno y oposición suelen elevar el conflicto y atacarse entre sí con fines estratégicos (Haselmayer, 2019). Dirigentes y activistas partidarios pueden polarizarse ideológicamente, pero por razones distintas a cambios previos en el electorado (Layman, Carsey y Horowitz, 2006, pp.94-100). Si esto persiste en el tiempo, es capaz de suscitar realineamientos partidarios e ideológicos en la sociedad (Levendusky, 2009) y creciente animosidad hacia el bando opuesto -polarización afectiva- en personas con una fuerte identidad partidaria (Mason, 2015).

$\mathrm{Si}$ los medios transmiten en forma consistente y duradera la imagen de una sociedad políticamente enfrentada, el público puede creer en ella y desarrollar sentimientos más negativos hacia el partido opuesto al propio (Levendusky y Malhotra, 2016).

Los principales medios argentinos no solo han presentado cada vez más al país como una sociedad dividida. Durante la gestión de Cambiemos, ligaron esa descripción a una defensa de las políticas neoliberales reinstauradas en el periodo -pese a las consecuencias ruinosas de los ensayos previos y a que las economías avanzadas y emergentes se alejan hoy del neoliberalismo (Gertz y Kharas, 2019)-. La grieta fue caracterizada como la oposición entre los que apoyaban el proyecto de una Argentina integrada al mundo -aunque implicara una dura austeridad y la pérdida de derechos e ingresos de trabajadores y retirados- y los que adherían a lo que se calificó difusamente de populismo, identificado como el causante histórico del retroceso del país y el empobrecimiento de sus habitantes.

Fue un esfuerzo para influir en las actitudes de los argentinos, que entre los 90 -en pleno auge de las reformas neoliberales de Carlos Menem- y el final del gobierno de Cristina Fernández de Kirchner, se movieron hacia posiciones más progresistas sobre la igualdad del ingreso y el equilibrio deseable entre propiedad privada y estatal (Jorge, 2018a).

Esa narrativa se reprodujo de modo acrítico, ignorando datos básicos de nuestra historia reciente. El ascenso de la pobreza -que en 1974 era inferior al 5\% de la población del Gran Buenos Aires-, la desindustrialización, el desempleo y el trabajo precario, el masivo endeudamiento externo y la fuga de capitales, hacen eclosión con el programa neoliberal de la dictadura entre 1976 y 1983, y se ahondan con el implementado desde 1989 hasta el colapso de diciembre de 2001.

En 1970 los niveles de ingreso por habitante y protección social de la Argentina eran similares a los de España y Portugal (Huber y Stephens, 2012, pp.208-39). Pero en 2000 los países ibéricos alcanzaban los promedios de Europa, debido a una experiencia mucho más 
prolongada con gobiernos progresistas y al positivo efecto de la integración a la comunidad europea sobre sus políticas del Estado de Bienestar, en contraste con el fuerte impacto negativo del Consenso de Washington en América Latina.

La crisis financiera de 2008-2009 golpeó a España, Portugal, Grecia, Italia e Irlanda. Por exigencia del FMI, la Unión Europea (UE) y el Banco Central Europeo, o de los mercados financieros internacionales, todos adoptaron planes de austeridad que dañaron su Estado de Bienestar y provocaron una epidemia electoral y creciente inestabilidad política (Bosco y Verney, 2012). En 2011 los gobiernos de los cinco países fueron desalojados. Un estudio en 26 naciones de la UE arrojó que la imposición externa de este tipo de políticas erosionó la confianza en los parlamentos nacionales y el apoyo a la democracia (Armingeon y Guthmann, 2014).

Rodrik (2011) subraya la dificultad de conciliar la híperglobalización con la democracia nacional, pues los ajustes que la integración profunda a la economía mundial impone a la gente son políticamente insustentables. Su capítulo dedicado al tema empieza con el colosal fracaso del experimento iniciado por Carlos Menem en 1989 y prolongado por Fernando de la Rúa, en ambos casos con protagonismo del ministro Domingo Cavallo (ibíd., pp.184-9).

Los tres pensaban que los problemas de la Argentina se resolverían a través de la integración profunda al mundo. Fue el Consenso de Washington llevado al extremo y el país se convirtió, por el calibre de sus reformas, en un modelo para el FMI. Pero tras la devaluación del real brasileño en 1999, el ingreso de capitales se detuvo, iniciando el proceso que llevó a la crisis de 2001. «[N]o importa cuánto haga un país. Los mercados financieros demandan más» (ibíd.: 119).

Pese al esfuerzo postrero de De la Rúa, «los inversores y acreedores se volvieron cada vez más escépticos de que el Congreso argentino, las provincias y la gente común fueran a tolerar las políticas de austeridad largamente desacreditadas en los países avanzados» (ibíd.: 188). El experimento fracasó porque «la política doméstica se cruzó en el camino de la híperglobalización» y al final -como cabe esperar en democracia- «emergió victoriosa» (ibíd.: 187).

Al ejecutar el tercer plan neoliberal de la Argentina, Mauricio Macri ignoró estas lecciones. Pese al expertise de sus tecnócratas, pronto los mercados le dieron la espalda, provocando la devaluación del peso y creciente inflación, recesión y pobreza. Macri recurrió al FMI y aplicó una extrema austeridad, asumiendo que con el masivo rescate del organismo podría estabilizar la economía y lograr su reelección apostando a la polarización y la campaña negativa. 
Para esto contó con apoyos en los medios. Una combinación de autoengaño, razonamiento motivado y complicidad dio forma a una burbuja mediática ${ }^{1}$ que instaló en propios y extraños incluida la mayoría de los encuestadores- la idea de un gobierno electoralmente competitivo. Su amplia derrota en las primarias puso fin a la ilusión y al exhausto experimento, ratificando así la supremacía de la política -y el impacto decisivo del voto económico en tiempos extraordinarios de crisis, bien documentado en estudios previos (Lewis-Beck y Costa Lobo, 2017)-.

Medios extranjeros insistieron, a la luz del caso argentino, en la necesidad de una reforma profunda de la arquitectura financiera internacional ${ }^{2}$. Ésta permite que grandes inversores subviertan las democracias, al forzarlas -amenazando con el vuelo de los capitales- a adoptar políticas gravosas para las mayorías. El actual modelo global del comercio y las finanzas es el producto de decisiones políticas y puede ser modificado por el mismo tipo de decisiones (Kuttner, 2018; Reich, 2015; Rodrik, 2011).

La globalización tiende a abrir una real fractura económica y cultural en las sociedades, entre una elite que se ve como beneficiaria -por sus habilidades y recursos para aprovechar los mercados y redes globales- y grandes grupos que se sienten ligados a la cultura y la economía local (Rodrik, 2018).

Inglehart (2016) destaca el grado en que el aumento de la desigualdad está asociado a los cambios en el equilibrio de poder entre las elites y las masas. La globalización reduce aún más el poder de negociación de los sindicatos, ya debilitados por la economía de servicios y la automatización, y la inteligencia artificial afecta a los empleos e ingresos de las profesiones de alta calificación. La riqueza tiende así a concentrarse en un grupo cada vez más pequeño de la sociedad.

Al retroceso de las políticas redistributivas ayudó el hecho de que los partidos progresistas de las economías avanzadas fueron por años virando su foco hacia cuestiones posmaterialistas como el medio ambiente y los derechos de género- demandadas por las nuevas generaciones de una clase media próspera. Grandes grupos de trabajadores con valores tradicionales

\footnotetext{
${ }^{1}$ Sobre el carácter y efectos de la burbuja mediática en la elección presidencial de 2016 en EE.UU., ver Shafer, J. (2017). The Media Bubble is Worse Than You Think. Politico Magazine, 25 de abril.

${ }^{2}$ Ver, por ejemplo, Blakeley, G. (2019). How the bond vigilantes are holding Argentina to ransom. New Statesman, 11 de septiembre. Grenville, S. (2019). Will the IMF Finally Learn From Argentina? Project Syndicate, 12 de septiembre. Recuperado de https://www.project-syndicate.org.
} 
José Eduardo Jorge, Gabriel Alberto Lamanna, Mara Leguizamón y Ulises Steciow Dejando atrás el discurso de la «grieta». ¿Cómo aumentar la confianza entre los argentinos?

migraron a partidos de derecha, hoy protagonistas de una reacción contra los cambios culturales de las últimas décadas.

Para reajustar el equilibrio de poder entre las masas y una pequeña elite se requieren -apunta Inglehart- nuevos realineamientos partidarios. La heterogénea mayoría que ve caer o estancarse su nivel de vida debe superar sus diferencias culturales internas y desarrollar una conciencia de sus intereses comunes, para que la cuestión redistributiva recobre un lugar central en la agenda política. Esto se volverá más probable a medida que aumenten la inquietud por la desigualdad y el acuerdo sobre temas culturales aún divisivos.

Aunque sea una sociedad de desarrollo intermedio -con un peso menor de las cuestiones culturales-, un programa de este tipo no deja de tener relevancia para el contexto político de la Argentina.

\section{Confianza social y confianza política}

Las crisis económicas, la desigualdad y el ascenso de la extrema derecha -que para algunos envuelven una crisis de la democracia (Mounk, 2018; Jorge, 2018b)- han acentuado hoy el interés público y académico por la confianza social y política (Uslaner, 2018; Zmerli y Van der Meer, 2017; Jorge, 2016a).

Los estudios acumulados por décadas sugieren que la confianza social entre los ciudadanos es esencial para la integración, cohesión y estabilidad de la sociedad (Uslaner, 2018, pp. 385-555; Nannestad, 2008; Welch et al., 2005), cuestiones clave en una era de cambios rápidos y conflictivos. La confianza entre las personas es un bien público que, al facilitar la cooperación en la solución de difíciles problemas de acción colectiva, promovería el buen gobierno, el crecimiento económico y el bienestar general (Putnam, 1993, 2000; Jorge, 2010, pp. 94-118), incluyendo el cobro de impuestos y el tamaño y sustentabilidad del Estado de Bienestar (Bjørnskov y Svendsen, 2013; Rothstein, 2010).

Como concepto central de la teoría del capital social, la confianza está ligada a la noción clásica de solidaridad. El reconocimiento de su importancia emergió en los 90, tras un largo periodo en que la discusión política, en el ethos de la globalización y el neoliberalismo, se enfocó solo en la libertad -y con una visión estrecha, centrada en la economía y el mercado libre- (Newton, 1999: 169).

Cuando la confianza es extendida, es más probable que los ciudadanos se vean como iguales, se respeten, sean solidarios y tengan un sentido de comunidad que permita superar las diferencias y reducir las conductas oportunistas (Putnam, 1993, p. 86). Una elevada confianza social facilita a la sociedad lograr el difícil equilibrio entre conflicto y consenso que distingue a 
la democracia, y penetra incluso en la esfera de las relaciones entre los dirigentes políticos (Inglehart, 1999). Un sentimiento de apego y lealtad a la comunidad hace menos aceptables social y políticamente conductas abusivas y predatorias frecuentes entre nosotros, como las prácticas rentísticas, la elusión y evasión impositiva y la fuga desenfadada de capitales (aún por los funcionarios públicos).

La noción de confianza política alude usualmente a la que tienen los ciudadanos en las instituciones de la democracia: el parlamento, el gobierno, los partidos y la justicia, a los que suelen sumarse la administración pública y la policía (Newton y Norris, 2000, p. 53). Alcanza también a la evaluación de los dirigentes y representantes electos.

El marco analítico más utilizado para su estudio es la versión expandida, desarrollada por Norris (2011), del concepto de apoyo político de Easton (1965). El apoyo de los ciudadanos al sistema político es esencial para su estabilidad. La confianza en instituciones y actores específicos se distingue del apoyo a entes más abstractos, como el Estado nación y los principios centrales del régimen de gobierno. Si la primera cae -por ejemplo durante una gran crisis económica-, esta adhesión difusa al sistema permite que éste siga operando. La estabilidad de la democracia descansa en buena medida en este mecanismo.

La confianza en la efectividad de las instituciones y la capacidad y compromiso de los representantes facilita la implementación de políticas aún si son objeto de desacuerdo. Un grado de escepticismo también es importante, pues los ciudadanos críticos se involucran activamente en política y ejercen control sobre los funcionarios. Pero si la desconfianza y el cinismo se generalizan, la gente puede retraerse de la política y abrir la puerta a alternativas anti-sistema.

El estudio de la confianza social y política afronta el problema de aislar causas y efectos (Newton, Stolle y Zmerli, 2018). Inicialmente, la hipótesis de la relación entre estas dos confianzas -esencial en la teoría del capital social de Putnam (1993) para explicar la calidad democrática- solo se observó en el nivel agregado de los países: los más altos en confianza social lo eran también en confianza política (Delhey y Newton 2005; Newton y Norris 2000). No surgía evidencia de que los individuos que confiaban en los demás lo hicieran a la vez en las instituciones. Pero esto ha sido verificado en trabajos recientes usando indicadores más precisos (Zmerli y Newton, 2008, 2011). La fuerza de la relación entre ambas confianzas podría variar en distintos momentos históricos, al cambiar el contexto sociopolítico (Liu y Stolle, 2017). Es difícil desentrañar la dirección causal en esta asociación. Si la confianza interpersonal facilita el buen gobierno y éste mejora la calidad de vida, haciendo aumentar la primera, ¿qué viene primero? Los dos podrían reforzarse mutuamente, de modo que la alta (o baja) confianza social alimentaría el buen (o mal) gobierno y se alimentaría de él. Más aún, las dos confianzas 
están insertas en una vasta red de factores interdependientes, entre otros el ingreso per cápita, la igualdad del ingreso, el nivel educativo, las divisiones sociales, el régimen de gobierno y el grado de transparencia.

Para mayor complejidad, hay dos tipos de confianza social: la particularizada, depositada en personas conocidas y similares a nosotros, y la generalizada, que alcanza a los extraños y a quienes no son como nosotros. La segunda es la más importante en la moderna sociedad urbana-donde debemos interactuar continuamente con personas desconocidas y de diverso origen- y es en el mundo mucho más rara que la primera, aunque ésta parece ser su prerrequisito (Welzel y Delhey, 2015; Delhey, Newton y Welzel, 2011; Jorge, 2016a). Además, la confianza en el gobierno, el parlamento y los partidos se distingue de la referida a instituciones políticamente más neutrales como la justicia, la policía y la administración pública. Según Rothstein y Stolle (2008), las tres últimas, en la medida que sean transparentes e imparciales en la sanción de conductas no cooperativas, son más importantes que las tres primeras - de carácter más partidista- en la creación de un clima favorable para la confianza social (Carlin y Love, 2016).

\section{Argentina en perspectiva comparada}

La confianza en los demás es un rasgo duradero de una sociedad, que refleja toda su herencia histórica en materia económica, política y cultural (Inglehart, 1999). Pero no es inamovible y se sabe de cambios significativos en el largo plazo. En Alemania occidental, la población que confiaba en la mayoría de la gente -indicador estándar de la confianza social- subió de $9 \%$ en 1948 a 45\% en 1993 (Newton et al., 2018, p.: 41). En EE.UU. bajó de 58\% en 1960 a 40\% en 1998 (Uslaner, 2002, p. 6). 


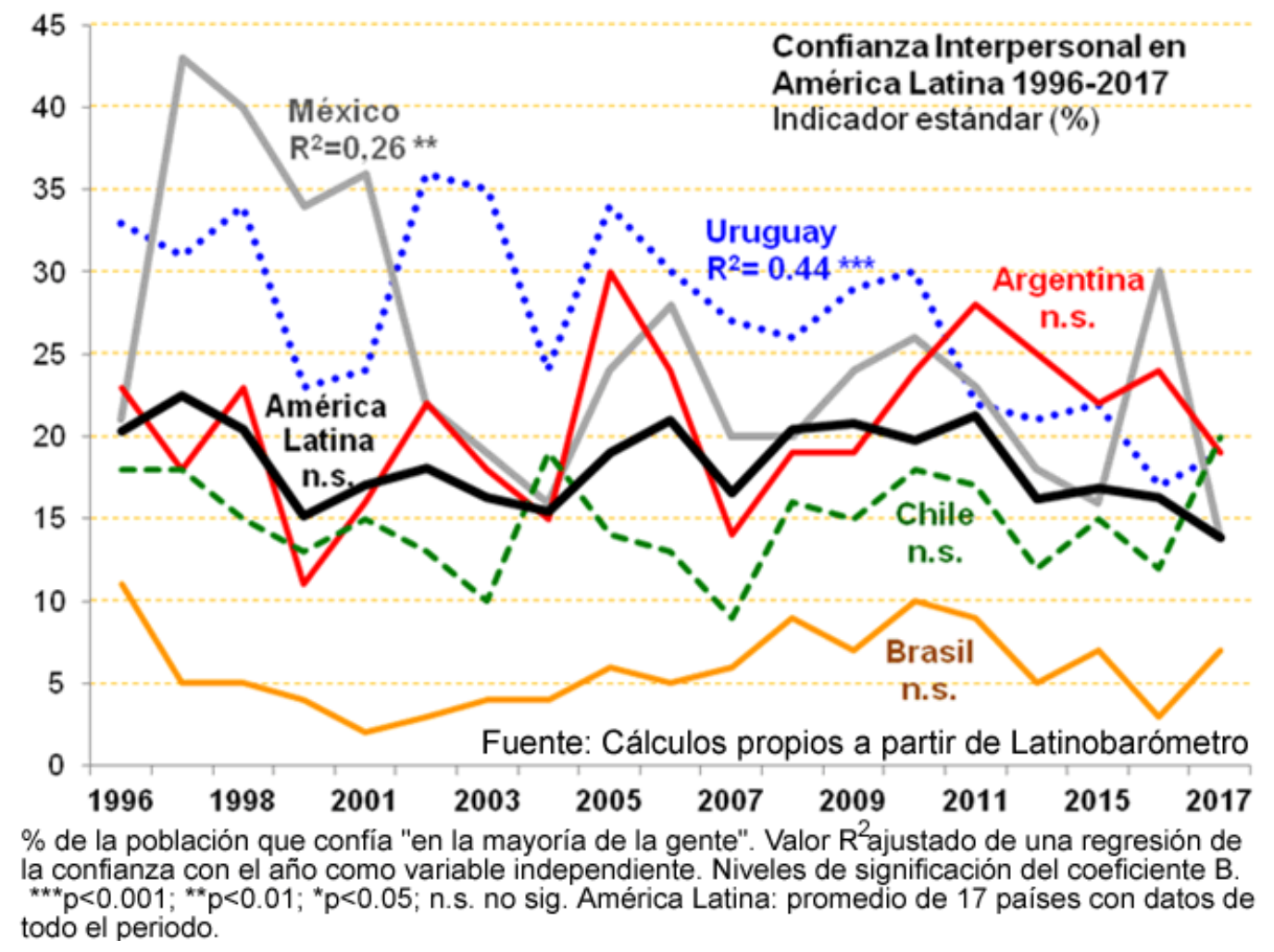

Figura 1

En Argentina este indicador ha oscilado en más de dos décadas en torno a su valor medio de $21 \%$ (Figura 1), sin una tendencia estadísticamente significativa de largo plazo a la suba o la baja (Jorge, 2015, p. 381). Una tendencia declinante surge en Uruguay y México, que hasta fecha reciente tenían los índices de confianza más altos de la región.

La confianza en las instituciones es más volátil, pues depende en mayor grado de contextos sociopolíticos específicos (Zmerli y Van der Meer, 2017, p. 4). Así lo reflejan las fuertes fluctuaciones de la confianza de los argentinos en el Congreso, los partidos y la justicia desde 1995 (Figura 2). En los tres casos, aunque la tendencia de largo plazo es neutra, la confianza se desploma entre picos y valles desde el inicio de la serie hasta un mínimo -inferior a 10\%durante la crisis de 2002. Todas $-y$ en especial el Congreso- inician entonces una franca recuperación que se revierte, según el caso, entre 2010 y 2013.

Muchos estudios arrojan que la confianza institucional está asociada a menudo -no solo en tiempos extraordinarios- al desempeño económico (Listhaug y Jakobsen, 2018). Más allá de los aspectos específicos de una institución que influyen en la evaluación que hacen de ella los argentinos, no solo las fluctuaciones del Congreso y los partidos, sino también las de la justicia, muestran una correspondencia general con los ciclos de aumento y descenso del ingreso por 
José Eduardo Jorge, Gabriel Alberto Lamanna, Mara Leguizamón y Ulises Steciow Dejando atrás el discurso de la «grieta». ¿Cómo aumentar la confianza entre los argentinos?

habitante en el periodo (Figura 3). En contraste, la confianza interpersonal exhibe un patrón mucho más estable (Figura 1).

La confianza en la policía es la única con una tendencia ascendente. Tras una caída inicial, sube hasta verse afectada por la crisis de 2001-2002 y luego termina de recuperarse para estabilizarse a partir de 2005.

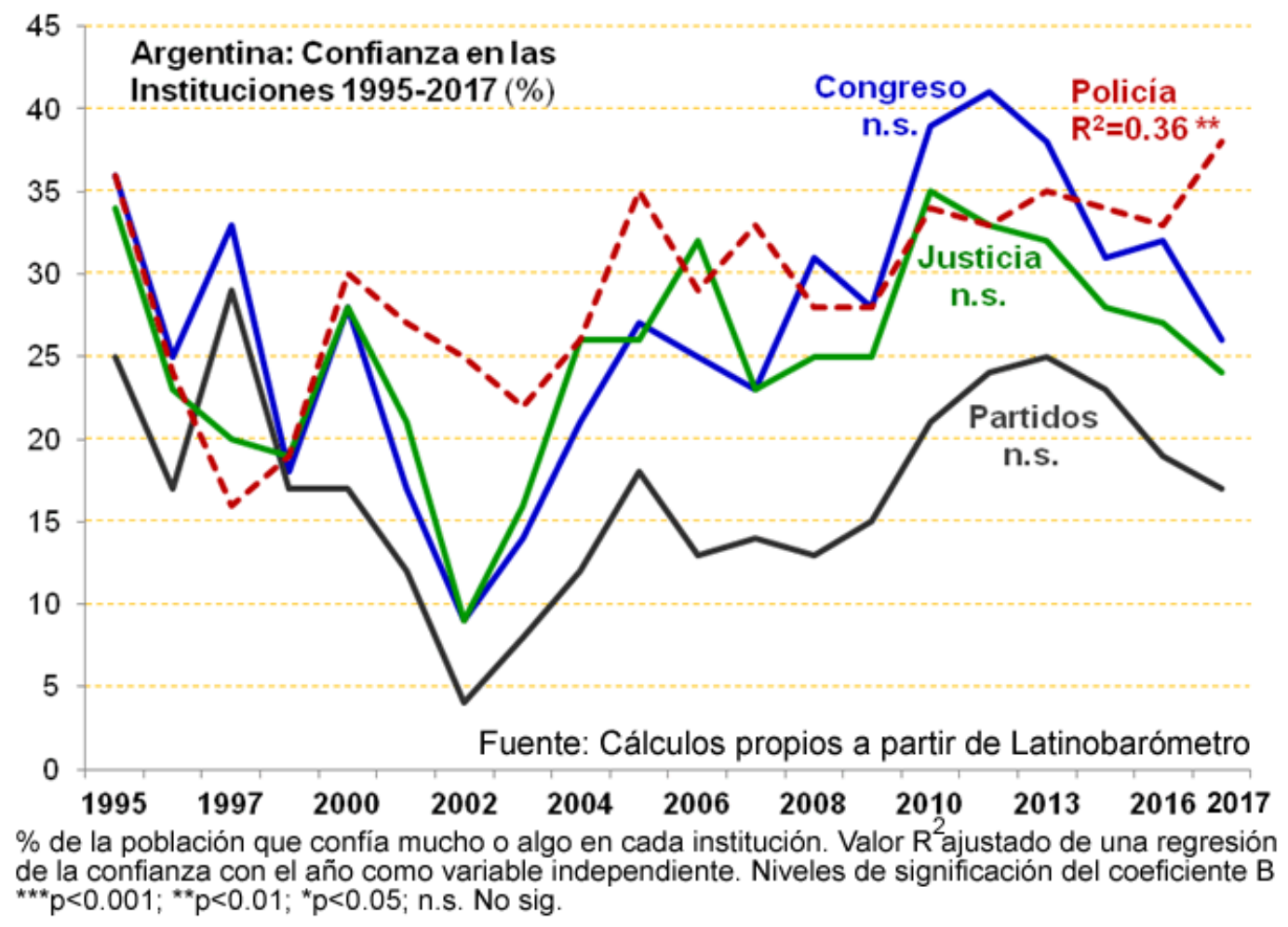

Figura 2 


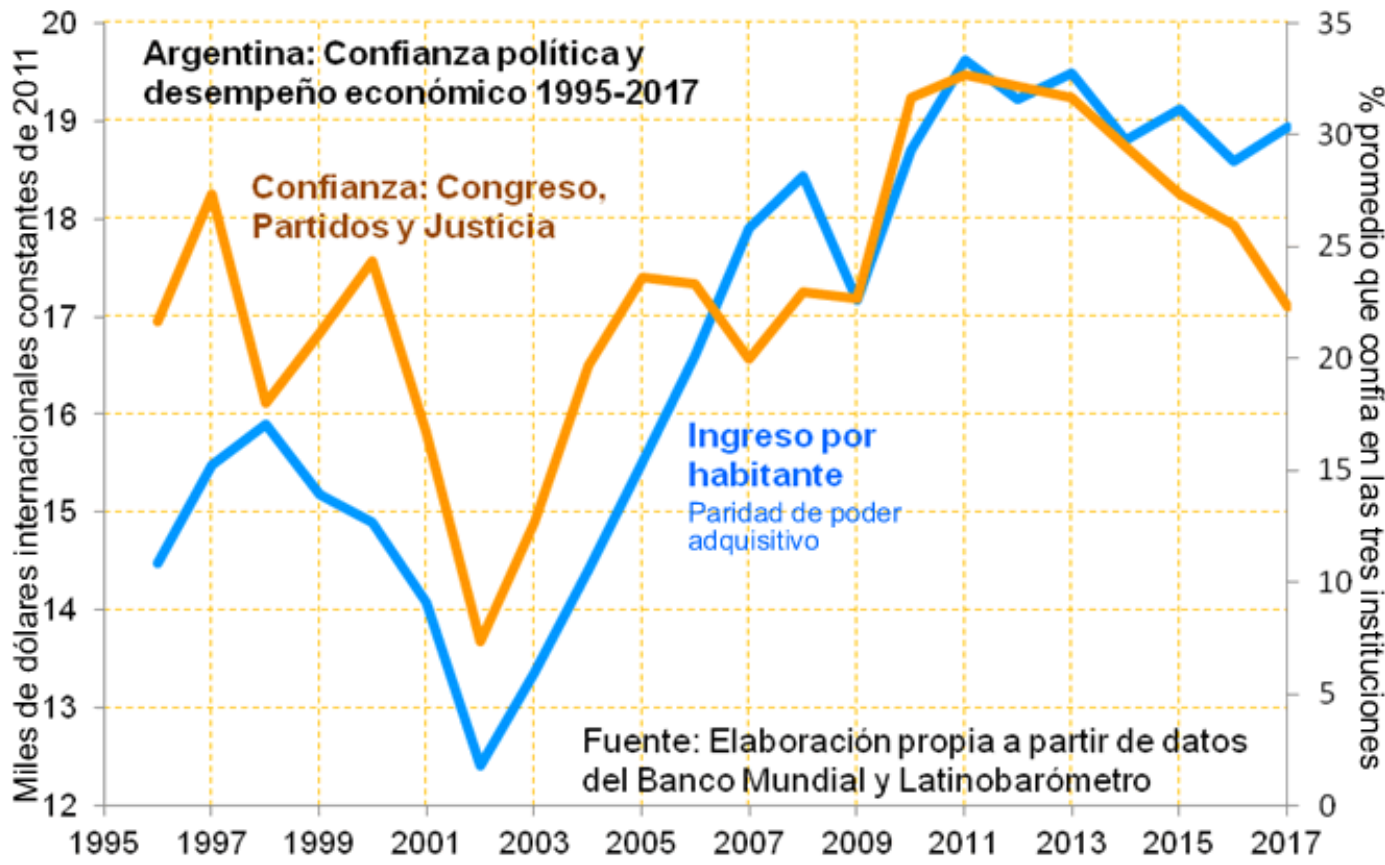

Figura 3

En los países industrializados la confianza institucional suele estar vinculada al desempeño en temas no económicos, como la salud pública, el cuidado de las personas mayores y el medio ambiente (Ibídem).

La confianza política también depende de quién gana o pierde las elecciones. Las personas que votaron por el partido ganador tienden a apoyar más al gobierno que las que votaron por el perdedor. Para algunos esto se agrava con la polarización partidaria -afectiva o ideológica- en el electorado.

La corrupción percibida daña directamente la confianza política. La desigualdad parece influir en modos más complejos. Uslaner (2008) sostiene que una alta desigualdad genera baja confianza social generalizada. Ésta alienta la corrupción, la cual reduce aún más la confianza y crea más desigualdad. Este círculo vicioso deprime también la confianza política y explicaría por qué la corrupción suele ser tan persistente y difícil de erradicar. La injusticia social hace que los ciudadanos crean que el sistema está armado contra ellos y se sientan menos cohibidos para actuar en forma oportunista. Además, fomenta el clientelismo político y distorsiona a las instituciones que deberían ser imparciales, como la justicia, la policía y los servicios sociales.

Zmerli y Castillo (2015) encuentran que en América Latina la confianza en las instituciones es afectada tanto por el nivel objetivo de desigualdad de un país como por el grado en que sus 
ciudadanos perciben que los ingresos están bien o mal distribuidos. Pero este efecto es más débil en los países más desiguales, donde es posible que grupos de bajos ingresos inflen su estatus o, habiendo incorporado las normas culturales del libre mercado, se culpen a sí mismos -no a las políticas públicas- por su situación (Ibíd.: 190).

Los índices de confianza social y política latinoamericanos están entre los más bajos del mundo (Jorge, 2016a). Lo vemos en la Figura 4, que presenta por región cultural datos del último sondeo de la WVS en 80 países entre 2005 y 2014. El cuadro de América Latina -la región más desigual del planeta, con una alta corrupción percibida- concuerda con hipótesis como la ya referida "trampa de la desigualdad" de Uslaner (2008) y el círculo vicioso formulado por Putnam (1993:177-81), en el que una deprimida confianza entre las personas, la falta de cooperación y el pobre desempeño institucional se refuerzan entre sí, creando un equilibrio social de baja intensidad y larga continuidad histórica (Jorge, 2010, pp.112-14).

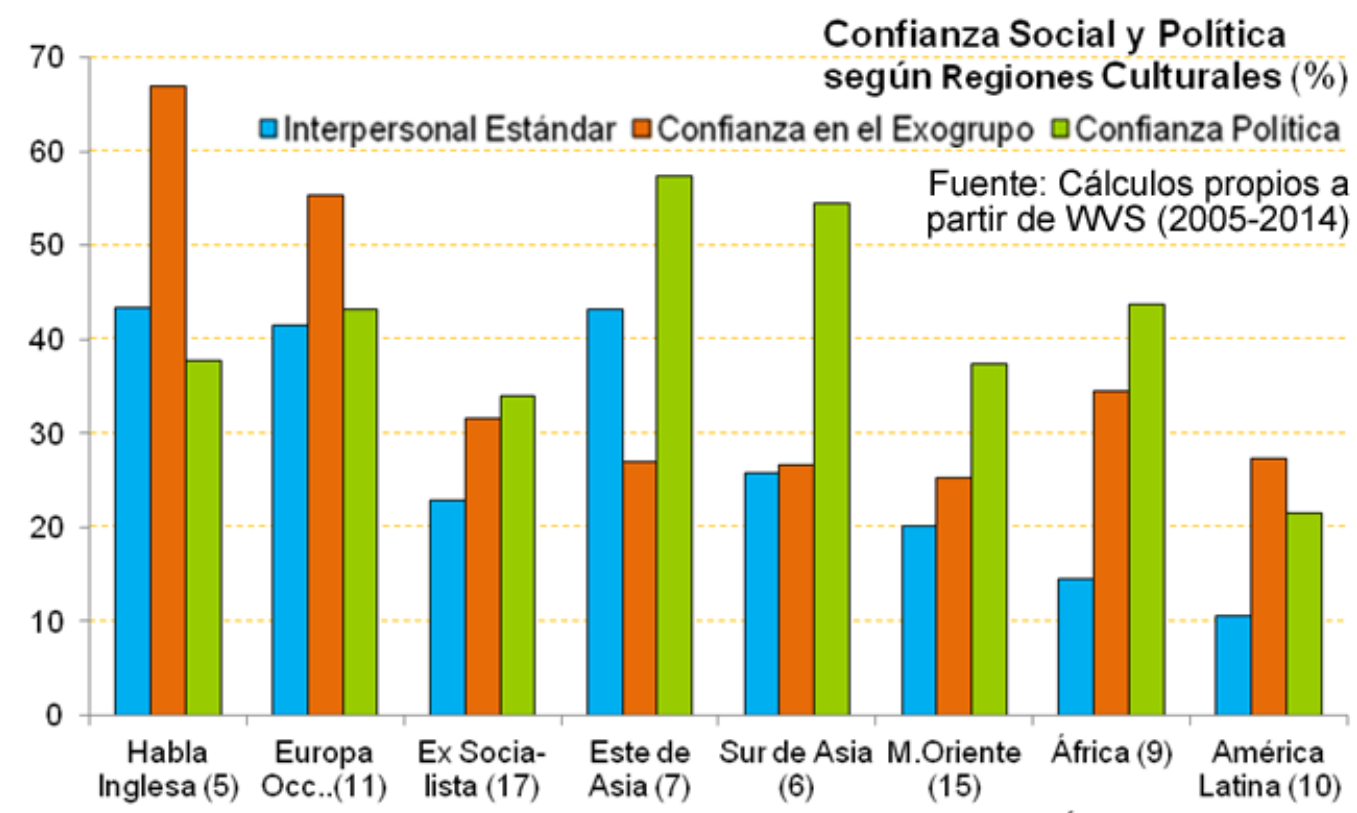

$\%$ de la población con valores mayores a 0.5 en cada escala de confianza. Último dato disponible de cada país ( $\mathrm{N}^{\circ}$ de países por región entre paréntesis)..Confianza política: promedio de las confianzas en el parlamento, gobierno, partidos, justicia, policia y funcionarios públicos. Confianza en el Exogrupo: promedio de las confianzas en las personas que conoce por primera vez, son de otra nacionalidad o de otra religión. Todas las escalas varían entre 0 y 1.

Figura 4

La Figura 4 revela empero que la confianza política no siempre es señal de calidad democrática. En el Este asiático, por ejemplo, su alto porcentaje debe mucho a China y Vietnam, donde confía en las instituciones el $85 \%$ y $97 \%$ de la población. Una autocracia puede 
lograr fuerte apoyo de los ciudadanos. En China lo explican el crecimiento económico, la tradición cultural, la percepción de que el gobierno responde a las demandas de la gente y una eficaz administración estatal (Tang, 2016, Rothstein, 2015).

El Este asiático tiene además una alta confianza social estándar -que llega a 63\% en China y $52 \%$ en Vietnam-. Pero el vínculo de las dos confianzas suma aquí una complejidad adicional.

Al decir que confían en la mayoría de la gente, los encuestados de países diversos suelen pensar en círculos diferentes de personas, al incluir en medida distinta a las que conocen y son como ellos y a las que no conocen y no son similares a ellos. Esta variabilidad del radio de confianza distorsiona las comparaciones entre países. En China, por ejemplo, se confía sobre todo en las personas cercanas. En otros países -entre ellos Argentina-, el radio se extiende a los no semejantes.

Las dos últimas ondas de la WVS incluyeron escalas para medir la confianza en el "endogrupo" -la familia, el vecindario y los conocidos- y el exogrupo: las personas que se conocen por primera vez y las que son de otra nacionalidad o religión (Jorge, 2016a). Las seis escalas originales son ordinales de cuatro puntos y las recodificamos para que tomen valores entre $0 \mathrm{y}$ 1 (Tabla 1 del Anexo). La Figura 4 muestra que la confianza en el exogrupo -un proxy del radio de confianza (Delhey et al, 2011: 798)- solo es alta en las dos regiones que integran la mayoría de las democracias industrializadas.

Análisis factorial de medidas de confianza social en el mundo Método de componentes principales. Rotación Promax, matriz de estructura Unidades de análisis: 104.776 encuestados en 77 países

\begin{tabular}{l|rr|rc|} 
& \multicolumn{4}{|c|}{ Componentes } \\
Grado de confianza en:: & Con medida estándar & Sin medida estándar \\
Familia & $\mathbf{1}$ & $\mathbf{2}$ & $\mathbf{1}$ & $\mathbf{2}$ \\
Vecindario & $-0,004$ & 0,732 & $-0,018$ & 0,725 \\
Gente que conoce personalmente & 0,380 & 0,774 & 0,368 & 0,779 \\
Gente que conoce por primera vez & 0,515 & 0,676 & 0,509 & 0,689 \\
Gente de otra religión & 0,763 & 0,325 & 0,757 & 0,344 \\
Gente de otra nacionalidad & 0,847 & 0,175 & 0,866 & 0,207 \\
La mayoria de la gente (estándar) & 0,858 & 0,180 & 0,874 & 0,212 \\
Autovalor & $\mathbf{0 , 4 0 5}$ & 0,222 & & \\
Varianza explicada (en \%) & 2,8 & 1,2 & 2,7 & 1,2 \\
KMO & 39,8 & 17,5 & 44,4 & 20,5 \\
& 0,746 & & 0,729 &
\end{tabular}

Fuente: Cálculos propios a partir de la base de datos de las ondas 5 y 6 de la WVS. Encuesta más reciente de cada país entre 2005 y 2014. Para el análisis el número de casos por país se igualó en 1.500 con la variable de ponderación S019 de la WVS. 
Figura 5

Análisis factorial de medidas de confianza social en Argentina 2013

Método de componentes principales. Rotación Promax, matriz de estructura Unidades de análisis: 920 encuestados

Grado de confianza en::
Familia
Vecindario
Gente que conoce personalmente
Gente que conoce por primera vez
Gente de otra religión
Gente de otra nacionalidad
La mayoria de la gente (estándar)
Autovalor
Varianza explicada (en \%)
KMO

\begin{tabular}{|cc|cc|}
\multicolumn{5}{|c|}{ Componentes } \\
Con medida estándar & \multicolumn{2}{|c|}{ Sin medida } & estándar \\
$\mathbf{1}$ & $\mathbf{2}$ & $\mathbf{1}$ & $\mathbf{2}$ \\
0,298 & $-0,624$ & 0,083 & 0,900 \\
0,633 & $-0,032$ & 0,577 & 0,485 \\
0,674 & $-0,059$ & 0,611 & 0,473 \\
0,624 & $\mathbf{0 , 5 1 1}$ & 0,675 & 0,047 \\
0,811 & 0,203 & 0,846 & 0,166 \\
0,811 & 0,225 & 0,855 & 0,156 \\
0,275 & $\mathbf{0 , 6 7 1}$ & & \\
2,7 & 1,1 & 2,7 & 1,0 \\
39,2 & 15,5 & 44,5 & 17,1 \\
0,729 & & 0,733 &
\end{tabular}

Fuente: Cálculos propios a partir de la base de datos Argentina 2013 de la WVS

Figura 6

Un análisis factorial en el nivel de individuos de los datos agregados de 77 países donde se relevaron todas las escalas arroja una solución de dos componentes (Figura 5). Uno de ellos reúne las medidas de confianza en las personas cercanas y conocidas; el otro, las correspondientes a los extraños y desemejantes. Sin embargo, la confianza en el vecindario y en los conocidos también muestra cargas positivas en el otro componente. Esto sugiere que los dos tipos de confianza -uno más particularizado y el otro más general- se solapan en algún grado. La confianza estándar dicotómica, al incorporarse al análisis, entra en el mismo componente que las escalas del exogrupo. Es pues un indicador válido de confianza social general, aunque impreciso al comparar sociedades donde el radio de "la mayoría de la gente" es muy variable (Delhey et al., 2011).

En Argentina (Figura 6) el endogrupo es connotado principalmente por la familia y, en menor medida, por vecinos y conocidos, que tienen cargas positivas más altas en el componente del exogrupo. La medida estándar connota sobre todo la confianza en los desconocidos. Un detalle de la distribución de la confianza de los argentinos en los seis grupos sociales se ve en la Figura 7. 


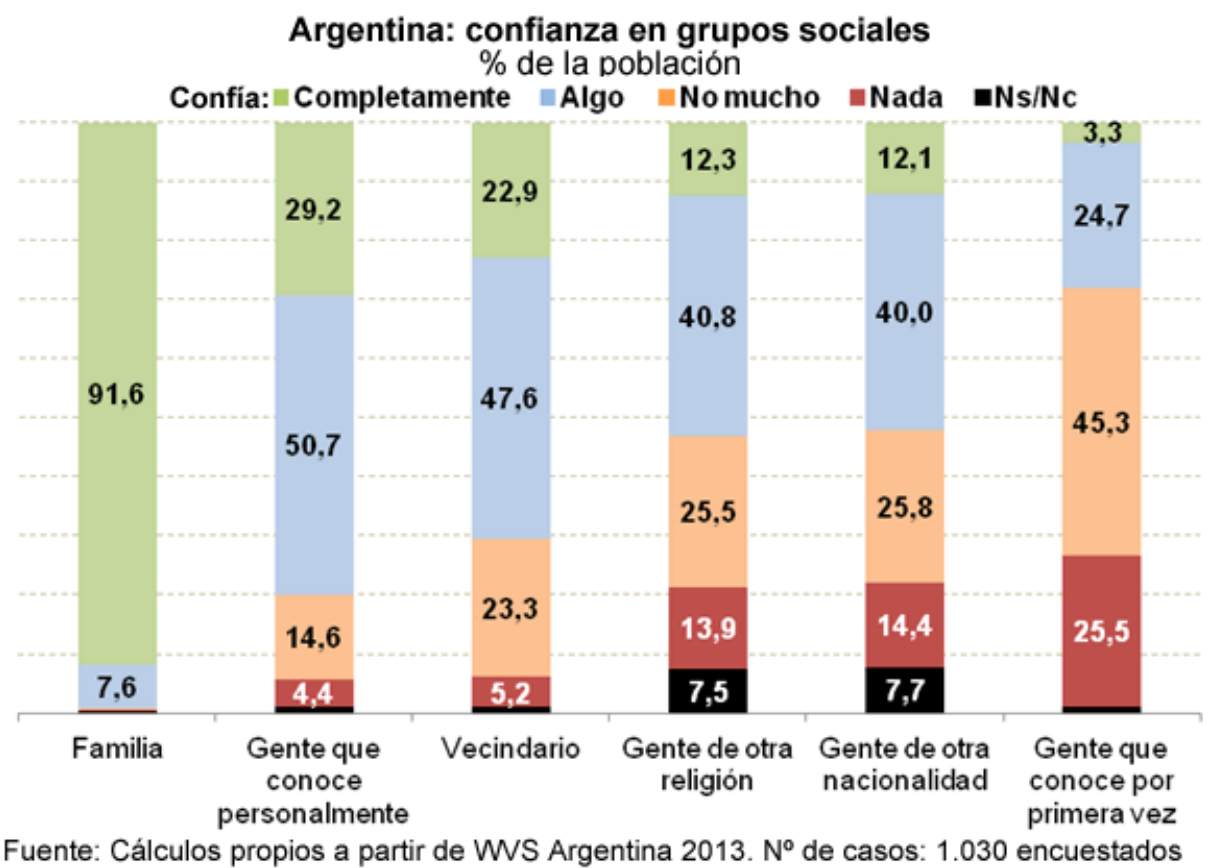

Figura 7

Los datos de la WVS arrojaron luz sobre hipótesis muy debatidas. La confianza particularizada (en el endogrupo) es un rasgo universal, no propio o exclusivo de comunidades pequeñas y homogéneas. En los 77 países relevados, confía en promedio en el endogrupo el 91\% de los encuestados (en Argentina, 95\%) (Figura 8), mientras solo el 35\% lo hace en el exogrupo (49\% en nuestro país). En Argentina el radio de confianza es grande, pero el nivel absoluto de confianza -la proporción de personas que confían en los demás- es pequeño (Ibídem: 794; Jorge, 2016a). China presenta la situación inversa. El nivel y el radio son ambos grandes en Suecia y Noruega.

La Figura 8 revela que todos los que confían en el exogrupo lo hacen también en el endogrupo (la ínfima diferencia es atribuible a errores de medición). Pero solo una porción de quienes confían en el endogrupo lo hacen en el exogrupo. Esto sugiere que la confianza particularizada es una condición necesaria pero no suficiente de la generalizada (Welzel y Delhey, 2015). Los datos no son consistentes con la hipótesis de que la confianza en el propio grupo implica la desconfianza en los extraños (Warren, 1999, p. 218) -la idea de nosotros contra ellos-. Tampoco con la que postula que todos los tipos de confianza derivan de una única predisposición psicológica a confiar adquirida en la vida temprana (Uslaner, 2002). 


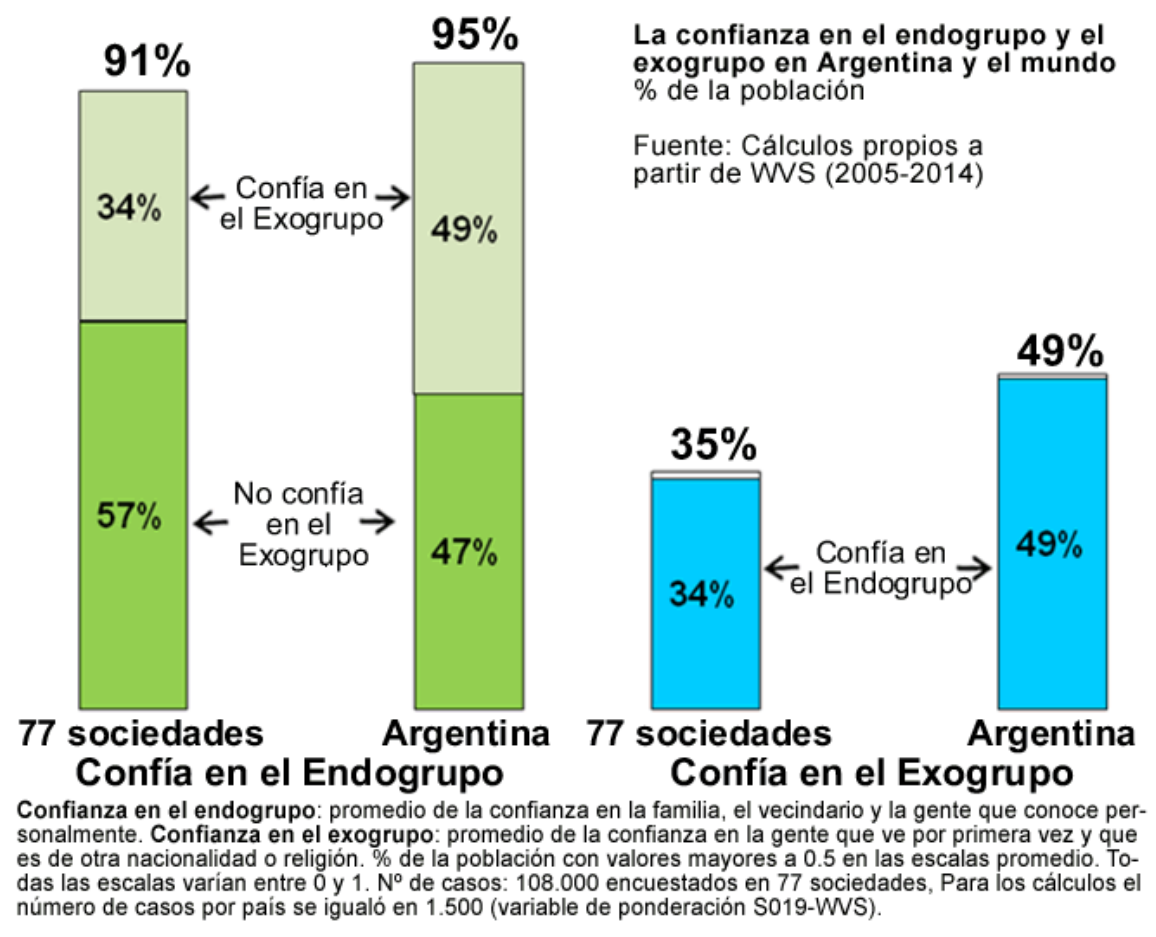

Figura 8

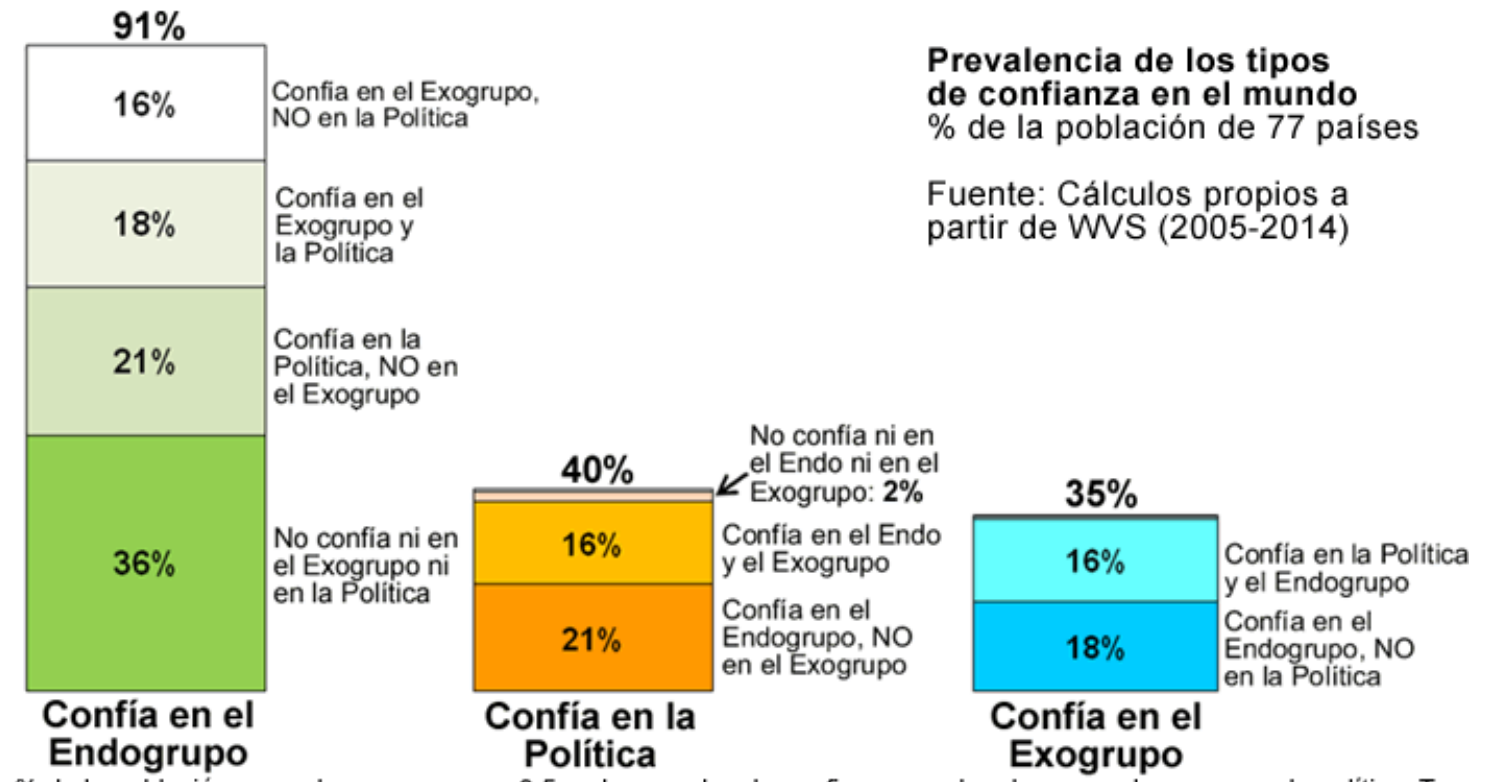

$\%$ de la población con valores mayores a 0.5 en las escalas de confianza en el endogrupo, el exogrupo y la política. Todas las escalas varian entre 0 y 1 . Confianza política: promedio de las confianzas en el parlamento, gobierno, partidos, justicia, policia y funcionarios públicos. $\mathrm{N}^{\circ}$ de casos: 108.000 encuestados en 77 sociedades. Último dato disponible de cada país. Para los cálculos el número de casos por país se igualó en 1.500 (variable de ponderación S019-WVS) 
Figura 9

Las mismas consideraciones se extienden a la confianza política ${ }^{3}$, que en el mundo es más frecuente que la depositada en el exogrupo (Figura 9). Entre los que confían en la política, una parte lo hace en el endogrupo pero no en el exogrupo -la otra parte confía en ambos-. Esto supone que la confianza política no está asociada siempre a la confianza social generalizada: puede apoyarse en la particularizada (y quizás fomentarla), como sucede en China y Vietnam ${ }^{4}$. En la Argentina la confianza en las instituciones es mucho menos frecuente que la que existe en el exogrupo (Figura 10).

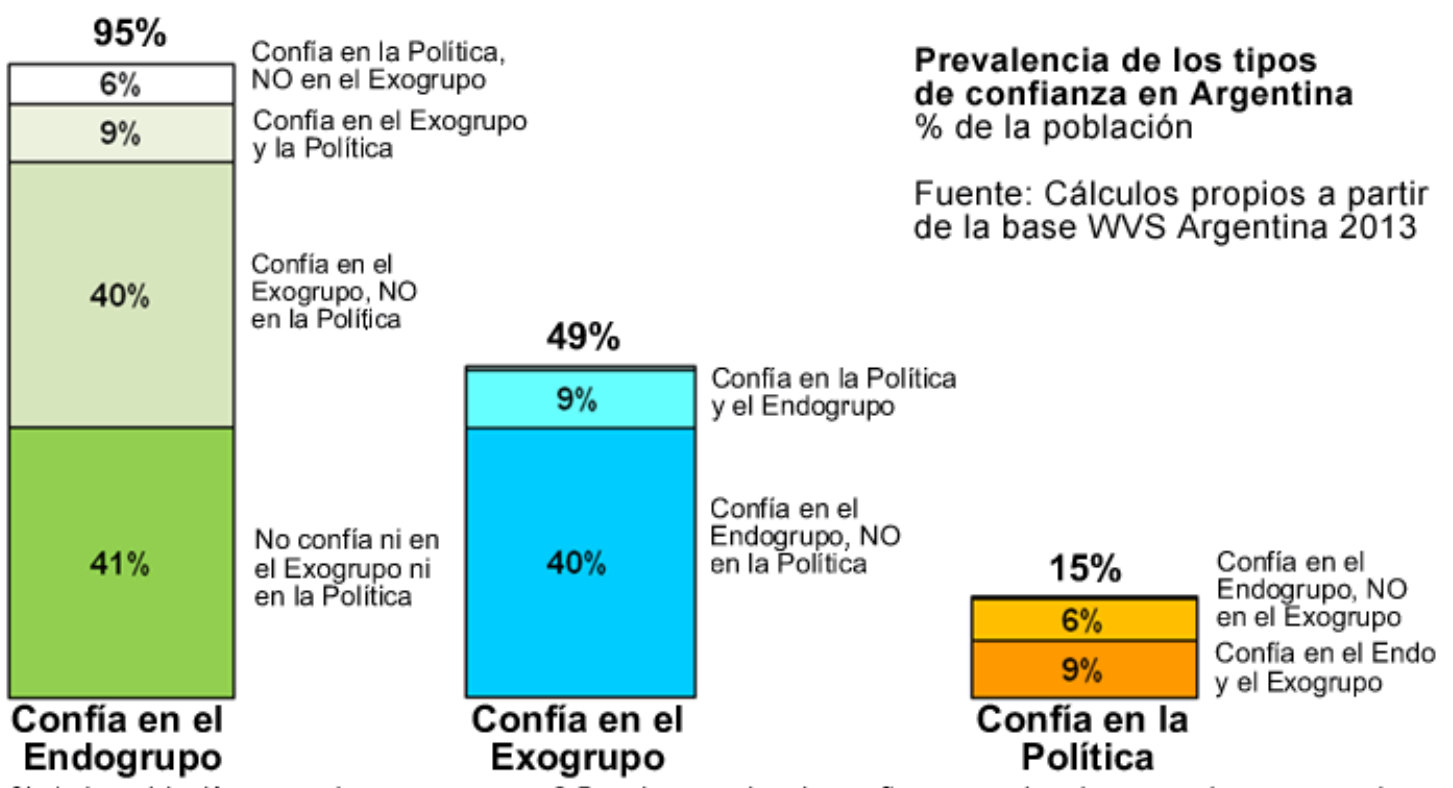

$\%$ de la población con valores mayores a 0.5 en las escalas de confianza en el endogrupo, el exogrupo y la política. Todas las escalas varian entre 0 y $1 . \mathrm{N}^{\circ}$ de casos: 1.030 encuestados.

Figura 10

\footnotetext{
${ }^{3}$ En el mundo y en nuestro país, un análisis factorial de las confianzas en las seis instituciones políticas arroja un solo componente.

${ }^{4}$ En estos países, la confianza política tiene una correlación más alta con la confianza en el endogrupo que con la del exogrupo.
} 
José Eduardo Jorge, Gabriel Alberto Lamanna, Mara Leguizamón y Ulises Steciow Dejando atrás el discurso de la «grieta». ¿Cómo aumentar la confianza entre los argentinos?

\section{¿Cómo promover la confianza?}

Indagaremos ahora los factores que influyen en la confianza social de los argentinos en el nivel individual. No buscamos dilucidar aquí las posibles relaciones causales de doble vía entre la confianza política y la que existe en los demás. Nuestros 22 modelos de regresión (Figuras 11 a 16) predicen diversos índices de confianza entre las personas. La confianza en las instituciones se introduce como uno de sus predictores y la interpretación de su posible impacto causal descansa en la teoría.

Pero las políticas públicas pueden tener consecuencias indirectas no previstas (e inadvertidas) sobre la confianza social al modificar en el largo plazo -por acción u omisión- las fuerzas que la modelan. Por ejemplo, Uslaner (2002, pp.181-9) sostiene que en EE.UU. la causa más importante del declive de la confianza desde los 60 es el aumento de la desigualdad del ingreso, atemperado en Europa por políticas específicas.

Una mejor comprensión de las fuerzas que dan forma a la confianza permitiría incorporar esta nueva dimensión a la evaluación de impacto de las políticas públicas y plantear acciones específicas por parte del Estado, movimientos sociales, ONG y otros entes. Este enfoque parece necesario en la Argentina y toda América Latina para romper el círculo vicioso que ha sustentado por largo tiempo los muy deprimidos niveles de confianza social y política -aunque éstos, a su vez, han sido históricamente un obstáculo principal para adoptar y mantener políticas capaces de cambiar el statu quo-.

La confianza social depende en parte de características de la sociedad como un todo. Los estudios destacan el efecto positivo del nivel de riqueza e igualdad del ingreso; de la calidad de la democracia, el estado de derecho y la transparencia, y de ciertos legados culturales -como el protestantismo- (Jorge, 2016a , pp.162-3; 2017). El conflicto interno, la inseguridad y las divisiones sociales - de riqueza y, a veces, étnicas- son influencias negativas.

El desarrollo tiende a elevar la confianza. Pero como sugiere el caso alemán desde la posguerra, el crecimiento económico debe acompañarse de políticas que lleven el bienestar a toda la sociedad y de instituciones democráticas y efectivas (Freitag y Bülhmann, 2009). En contraste, tras décadas de crecimiento y democracia estable, Chile tiene una muy alta desigualdad. Desde mediados de los 90 su confianza social estándar es en promedio $15 \%$ y la confianza política ha caído en forma pronunciada.

Con datos de las bases para la Argentina WVS 2013 y Latinobarómetro 2015, nuestras regresiones indagan los determinantes de cuatro tipos de confianza social entre los argentinos: estándar, generalizada, en el exogrupo y en el endogrupo. La confianza generalizada es una 
medida ajustada del porcentaje de argentinos que dicen confiar en la mayoría de la gente, que excluye a quienes no confían en el exogrupo (Jorge, 2016ạ, pp.56-8)

Hemos seleccionado de las bases de datos una amplia variedad de predictores (ver Tabla del Anexo) para contrastar seis enfoques teóricos (Delhey y Newton, 2003; Jorge, 2010. Pp. 27387). Cuatro de éstos subrayan cualidades de los individuos que los harían más proclives a confiar en los demás: 1) personalidad, 2) gozar de bienestar y éxito en la vida, y participar en 3) asociaciones voluntarias o 4) redes sociales informales. Además, la confianza sería más probable en 5) barrios o comunidades y 6 ) países con ciertas características. Todas las variables de los modelos son escalas entre 0 y 1 .

Algunas cualidades de los países o sociedades como un todo tienen su manifestación en el nivel de los individuos y forman parte de nuestros predictores en esta forma desagregada (Welzel y Delhey, 2015, p. 7). Una de ellas es la confianza política, cuyos distintos indicadores -referidos a las seis instituciones de gobierno, las tres instituciones políticas y la justicia y la policía (ver Tabla del Anexo)- son predictores significativos en todos los modelos, incluido el del endogrupo. También es relevante el respeto percibido por los derechos humanos, otro aspecto de la calidad institucional.

Trabajar sobre la confianza política -cuyo influjo ya fue observado en las ondas 1999 y 2006 de la WVS (Jorge, 2010, pp. 288-96)- parece ser una de las llaves para elevar la confianza social. Los análisis con Latinobarómetro (Figura 12) sugieren un papel para la trampa de la desigualdad de Uslaner: la transparencia percibida en el gobierno desplaza a la confianza política como determinante de la confianza en los demás y sobre ésta influye además el grado de justicia social percibido en el país. Seleccionamos la onda 2015 de Latinobarómetro porque incluye preguntas que permiten construir proxies de predictores socioculturales usados en los modelos con datos de la WVS.

El desarrollo económico y humano produce cambios en la cultura y la estructura social que luego impactan en la esfera político-institucional (Jorge, 2016b). A través del reemplazo generacional, en la sociedad posindustrial emerge un síndrome de valores culturales prosociales que entrañan la confianza generalizada. Este sistema, presente también en el nivel individual $-y$ que ha sido medido con distintos indicadores bajo los rótulos de "valores de autoexpresión" (Inglehart y Welzel, 2005) y valores de emancipación (Welzel 2013)- prioriza la libertad de elección, la igualdad de oportunidades, la participación autónoma, la diversidad y el respeto por los otros (Jorge, 2018b, 2015).

Más ampliamente, el desarrollo avanzado -a través de estos valores y la expansión de la educación, la información, el trabajo creativo y la participación en movimientos socialesenvuelve un proceso de empoderamiento humano que tiende a emancipar a los individuos de 
la dominación externa -y que en el nivel de los países incluye la ampliación de los derechos de las personas e instituciones efectivas que los protegen- (Welzel, 2014).

El proceso alienta la confianza generalizada. La sociedad moderna reduce la dependencia de las personas de su propio grupo, aumenta sus oportunidades de cooperar con provecho con miembros de otros grupos y las provee de los valores y habilidades para hacerlo.

Una parte de la confianza en el exogrupo parece originarse en la que existe en el endogrupo. El individuo desarrolla una expectativa general sobre la confiabilidad de la persona promedio en su sociedad a partir de sus experiencias en contextos localizados: la familia, el barrio, el trabajo o el club (Glanville, Andersson y Paxton, 2013). En Argentina, la importancia que asignamos a los amigos es un predictor de la confianza generalizada (Figura 13).

Pero otra parte de la confianza en el exogrupo sería independiente de este proceso y tendría como fuente el empoderamiento de las personas (Welzel y Delhey, 2015). Los modelos de la Figura 14 incluyen la confianza en el endogrupo entre los predictores de la depositada en el exogrupo. Esto implica que los demás predictores explican la parte de esta última que existe con independencia de la primera. Entre ellos, el índice de empoderamiento es la influencia más poderosa: un aumento de 1 punto de este índice incrementa en 0,193 puntos la confianza en el exogrupo (modelo 4). También es muy importante el influjo de los valores de autoexpresión y la confianza en las instituciones de gobierno. La religiosidad y la intolerancia étnica y religiosa tienen un pequeño efecto negativo.

Los valores de autoexpresión o emancipación y algunos indicadores del proceso de movilización cognoscitiva propio del desarrollo posindustrial (Jorge, 2010, p. 91) -que Welzel integra a su índice de empoderamiento- promueven la confianza estándar y generalizada (Figuras 11 y 13). Ambas son fomentadas además por la satisfacción con las finanzas del hogar. Pero el nivel de ingreso familiar, manteniendo constantes las demás influencias, tiene un impacto negativo sobre estas dos confianzas y la del exogrupo. La inseguridad del barrio también reduce la confianza estándar y generalizada (Figuras 12 y 13), pero no es significativa para la del exogrupo.

La confianza en el endogrupo (Figura 15) es impulsada con fuerza por las relaciones de amistad y los valores emancipatorios y, en un grado menor, por la satisfacción con la vida y el sentimiento de libertad y control sobre ésta. Además, está asociada positivamente con la confianza política. El tamaño de la localidad y la intolerancia étnica la afectan negativamente.

El asociacionismo voluntario tiene en nuestros modelos un efecto negativo o no significativo. Esto concuerda con análisis previos (Jorge, 2016a; 2010, pp.288-96) y la investigación internacional (Newton et al., 2018). 
Quizás la principal conclusión para la política pública que emerge de nuestro examen apunta al rumbo que debería imprimirse al desarrollo económico y social de la Argentina y a la necesidad de profundizar las tareas de construcción democrática. Políticas universales que promuevan la igualdad; un sistema institucional y un aparato estatal imparciales, efectivos y transparentes, que sancionen las conductas no cooperativas; y dirigentes que respondan a las demandas de la población, son las vías para elevar gradualmente la confianza social y política y romper los círculos viciosos que las han mantenido deprimidas durante décadas. 
José Eduardo Jorge, Gabriel Alberto Lamanna, Mara Leguizamón y Ulises Steciow Dejando atrás el discurso de la «grieta». ¿Cómo aumentar la confianza entre los argentinos?

Determinantes de la Confianza Interpersonal Estándar: Argentina 2013 Análisis de regresión logística

\begin{tabular}{|c|c|c|c|c|}
\hline & Modelo 1 & Modelo 2 & Modelo 3 & Modelo 4 \\
\hline \multicolumn{5}{|l|}{ Valores } \\
\hline $\begin{array}{l}\text { Valores de Autoexpresión } \\
\text { (Inglehart y Welzel, 2005) }\end{array}$ & $\begin{array}{r}1,217 \dagger \\
(0,702)\end{array}$ & $\begin{array}{l}1,274 \dagger \\
(0,703)\end{array}$ & & \\
\hline $\begin{array}{l}\text { Valores de Emancipación } \\
\text { (Welzel, 2013) }\end{array}$ & & & $\begin{array}{l}0,390 \dagger \\
(0,721)\end{array}$ & \\
\hline \multicolumn{5}{|l|}{ Desarrollo Humano } \\
\hline $\begin{array}{l}\text { Empoderamiento } \\
\text { (Welzel y Delhey, 2015) }\end{array}$ & & & & $\begin{array}{r}0,379 \mathrm{~ns} \\
(0,708)\end{array}$ \\
\hline $\begin{array}{l}\text { Dimensión Institucional } \\
\text { Confianza en las institu- } \\
\text { ciones de gobierno }\end{array}$ & & $\begin{array}{l}0,691 \mathrm{~ns} \\
(0,498)\end{array}$ & & \\
\hline $\begin{array}{l}\text { Confianza en las institu- } \\
\text { ciones politicas }\end{array}$ & $\begin{array}{r}0,773 \dagger \\
(0,426)\end{array}$ & & $\begin{array}{c}0,780 \dagger \\
(0,435)\end{array}$ & $\begin{array}{c}0,990^{\star *} \\
(0,394)\end{array}$ \\
\hline $\begin{array}{l}\text { Respeto percibido } \\
\text { por los DDHH }\end{array}$ & $\begin{array}{r}1,543^{* * *} \\
(0,347)\end{array}$ & $\begin{array}{l}1,609^{* * *} \\
(0,345)\end{array}$ & $\begin{array}{r}1,661^{* * *} \\
(0,354)\end{array}$ & $\begin{array}{r}1,435 * * * \\
(0,321)\end{array}$ \\
\hline \multicolumn{5}{|l|}{ Bienestar Individual } \\
\hline $\begin{array}{l}\text { Satisfacción con las } \\
\text { finanzas del hogar }\end{array}$ & $\begin{array}{l}1,952^{* x *} \\
(0,550)\end{array}$ & $\begin{array}{l}1,969^{* * *} \\
(0,548)\end{array}$ & $\begin{array}{r}1,647^{\star *} \\
(0,552)\end{array}$ & $\begin{array}{r}1,865^{* * *} \\
(0,510)\end{array}$ \\
\hline Participación Social & & & & \\
\hline Asociacionismo voluntario & $\begin{array}{l}-1,228 \dagger \\
(0,694)\end{array}$ & $\begin{array}{l}-1,196 \dagger \\
(0,690)\end{array}$ & $\begin{array}{l}-1,381 \dagger \\
(0,721)\end{array}$ & $\begin{array}{l}-1,326^{*} \\
(0,661)\end{array}$ \\
\hline Importancia de los amigos & $\begin{array}{c}0,841 \\
(0,440)\end{array}$ & $\begin{array}{r}0,810 \dagger \\
(0,444)\end{array}$ & $\begin{array}{c}0,948 * \\
(0,450)\end{array}$ & $\begin{array}{r}0,761 \dagger \\
(0,404)\end{array}$ \\
\hline $\begin{array}{l}\text { Actividad en movimientos } \\
\text { sociales }\end{array}$ & & & $\begin{array}{r}0,402 \mathrm{~ns} \\
(0,410)\end{array}$ & \\
\hline \multicolumn{5}{|l|}{ Personalidad } \\
\hline Religiosidad & $\begin{array}{l}-1,302^{* \star *} \\
(0,398)\end{array}$ & $\begin{array}{l}-1,306^{\star \star *} \\
(0,403)\end{array}$ & $\begin{array}{l}-1,369^{\star \star *} \\
(0,400)\end{array}$ & $\begin{array}{l}-1,278^{\star \star *} \\
(0,364)\end{array}$ \\
\hline Movilización Cogno & & & & \\
\hline Nivel educativo & $\begin{array}{l}-0,320 \mathrm{~ns} \\
(0,374)\end{array}$ & $\begin{array}{l}-0,311 \mathrm{~ns} \\
(0,373)\end{array}$ & $\begin{array}{l}-0,295 \mathrm{~ns} \\
(0,379)\end{array}$ & \\
\hline Trabajo estimulante & $\begin{array}{c}0,838 * \\
(0,408)\end{array}$ & $\begin{array}{c}0,880 * \\
(0,407)\end{array}$ & $\begin{array}{c}0,903 * \\
(0,415)\end{array}$ & \\
\hline $\begin{array}{l}\text { Información: diversidad } \\
\text { de fuentes }\end{array}$ & $\begin{array}{c}-0,986 \dagger \\
(0,522)\end{array}$ & $\begin{array}{c}-0,999 \dagger \\
(0,522)\end{array}$ & $\begin{array}{l}-0,773 \mathrm{~ns} \\
(0,527)\end{array}$ & \\
\hline \multicolumn{5}{|l|}{ Variables Demográficas } \\
\hline $\begin{array}{l}\text { Nivel de ingreso familiar } \\
\text { (en deciles) }\end{array}$ & $\begin{array}{l}-1,041 \dagger \\
(0,628)\end{array}$ & $\begin{array}{l}-1,039 \dagger \\
(0,626)\end{array}$ & $\begin{array}{l}-1,125 \dagger \\
(0,638)\end{array}$ & $\begin{array}{l}-0,669 \mathrm{~ns} \\
(0,564)\end{array}$ \\
\hline Edad & $\begin{array}{c}0,385 \mathrm{~ns} \\
(0,515)\end{array}$ & $\begin{array}{c}0,415 \mathrm{~ns} \\
(0,515)\end{array}$ & $\begin{array}{c}0,300 \mathrm{~ns} \\
(0,525)\end{array}$ & $\begin{array}{c}0,863 * \\
(0,449)\end{array}$ \\
\hline Género: mujer & $\begin{array}{l}-0,001 \mathrm{~ns} \\
(0,198)\end{array}$ & $\begin{array}{c}-0,016 \mathrm{~ns} \\
(0,199)\end{array}$ & $\begin{array}{c}-0,059 \text { ns } \\
(0,202)\end{array}$ & $\begin{array}{r}0,057 \mathrm{~ns} \\
(0,180)\end{array}$ \\
\hline Constante & $\begin{array}{l}-3,267^{* * *} \\
(0,695)\end{array}$ & $\begin{array}{l}-3,281^{* \star *} \\
(0,695)\end{array}$ & $\begin{array}{l}-3,001^{* * *} \\
(0,740)\end{array}$ & $\begin{array}{c}-3,617^{* * *} \\
(0,598)\end{array}$ \\
\hline Pseudo $\mathbf{R}^{2}$ Nagelkerke & 0,17 & 0,17 & 0,18 & 0,15 \\
\hline $\mathrm{N}^{\circ}$ de casos & 792 & 787 & 774 & 896 \\
\hline
\end{tabular}

Fuente: Cálculos propios a partir de la base Argentina 2013 de la WVS. Las entradas son coeficientes de regresión logistica. Errores estándar entre parén-tesis. Variable dependiente: Confianza Interpersonal (indicador estándar). Variables independientes: ver defi nición en la Tabla del Anexo: ${ }^{* x *} p<0.001 ;{ }^{* *} p<0.01 ;{ }^{*} p<0,05 ; \dagger p<0.1$; ns: no significativo

Figura 11 
José Eduardo Jorge, Gabriel Alberto Lamanna, Mara Leguizamón y Ulises Steciow Dejando atrás el discurso de la «grieta». ¿Cómo aumentar la confianza entre los argentinos?

Determinantes de la Confianza Interpersonal Estándar: Argentina 2015

Análisis de regresión logística

\begin{tabular}{|c|c|c|c|c|c|c|}
\hline & Modelo 1 & Modelo 2 & Modelo 3 & Modelo 4 & Modelo 5 & Modelo 6 \\
\hline \multicolumn{7}{|l|}{ Desarrollo Humano } \\
\hline $\begin{array}{l}\text { Empoderamiento } \\
\text { (proxy) }\end{array}$ & & & & & $\begin{array}{l}1,111^{*} \\
(0,562)\end{array}$ & $\begin{array}{l}1,130 \text { * } \\
(0,563)\end{array}$ \\
\hline $\begin{array}{l}\text { Dimensión Institucional } \\
\text { Confianza en las Institu- } \\
\text { ciones de Gobierno }\end{array}$ & $\begin{array}{l}1,692^{* *} \\
(0,355)\end{array}$ & $\begin{array}{l}1,198^{\star *} \\
(0,386)\end{array}$ & $\begin{array}{l}0,672 \mathrm{~ns} \\
(0,425)\end{array}$ & & & \\
\hline $\begin{array}{l}\text { Transparencia percibida } \\
\text { en el Estado y gobierno }\end{array}$ & & & $\begin{array}{c}0,976^{\star \star} \\
(0,308)\end{array}$ & $\begin{array}{l}1,169^{* * *} \\
(0,283)\end{array}$ & $\begin{array}{l}1,144^{* \star *} \\
(0,283)\end{array}$ & $\begin{array}{l}1,085^{\star * \pi} \\
(0,285)\end{array}$ \\
\hline $\begin{array}{l}\text { Grado de justicia social } \\
\text { percibido en el país }\end{array}$ & & $\begin{array}{l}1,089^{\star \star \star} \\
(0,340)\end{array}$ & $\begin{array}{c}0,724^{*} \\
(0,365)\end{array}$ & {$\left[\begin{array}{c}0,853^{*} \\
(0,355)\end{array}\right.$} & $\begin{array}{r}0,841^{*} \\
(0,355)\end{array}$ & $\begin{array}{c}0,815^{\star} \\
(0,357)\end{array}$ \\
\hline $\begin{array}{l}\text { Policia: calidad percibida } \\
\text { (indice de } 5 \text { items) }\end{array}$ & & & & & & $\begin{array}{r}0,857 \dagger \\
(0,468)\end{array}$ \\
\hline $\begin{array}{l}\text { Comunidad } \\
\text { Inseguridad del barrio: } \\
\text { robos frecuentes }\end{array}$ & $\begin{array}{l}-0,492 * \\
(0,241)\end{array}$ & $\begin{array}{l}-0,380 \mathrm{~ns} \\
(0,247)\end{array}$ & $\begin{array}{l}-0,370 \mathrm{~ns} \\
(0,250)\end{array}$ & $\begin{array}{l}-0,401 \dagger \\
(0,249)\end{array}$ & $\begin{array}{l}-0,414 \dagger \\
(0,250)\end{array}$ & $\begin{array}{l}-0,379 \text { ns } \\
(0,251)\end{array}$ \\
\hline $\begin{array}{l}\text { Intolerancia étnica: } \\
\text { inmigrantes }\end{array}$ & $\begin{array}{l}-0,717^{* \star} \\
(0,260)\end{array}$ & $\begin{array}{l}-0,696 \text { ** } \\
(0,265)\end{array}$ & $\begin{array}{l}-0,684 * * \\
(0,268)\end{array}$ & $\begin{array}{l}-0,704 * * \\
(0,267)\end{array}$ & $\begin{array}{l}-0,675^{\star \star} \\
(0,271)\end{array}$ & $\begin{array}{l}-0,679 * \star \\
(0,271)\end{array}$ \\
\hline $\begin{array}{l}\text { Variables demográficas } \\
\text { Nivel educativo }\end{array}$ & $\begin{array}{l}0,695^{*} \\
(0,321)\end{array}$ & $\begin{array}{r}0,727^{\star} \\
(0,325)\end{array}$ & $\begin{array}{r}0,727^{*} \\
(0,329)\end{array}$ & $\begin{array}{l}0,798^{\star *} \\
(0,326)\end{array}$ & & \\
\hline Nivel socioeconómico & $\begin{array}{l}0,420 \mathrm{~ns} \\
(0,407)\end{array}$ & {$\left[\begin{array}{c}0,398 \mathrm{~ns} \\
(0,417)\end{array}\right.$} & $\begin{array}{c}0,372 \mathrm{~ns} \\
(0,422)\end{array}$ & {$\left[\begin{array}{c}0,320 \mathrm{~ns} \\
(0,421)\end{array}\right.$} & $\begin{array}{l}0,392 \mathrm{~ns} \\
(0,422)\end{array}$ & $\begin{array}{l}0,412 \mathrm{~ns} \\
(0,423)\end{array}$ \\
\hline Edad & $\begin{array}{l}0,183 \mathrm{~ns} \\
(0,375)\end{array}$ & $\begin{array}{c}0,116 \mathrm{~ns} \\
(0,380)\end{array}$ & $\begin{array}{c}0,127 \mathrm{~ns} \\
(0,384)\end{array}$ & $\begin{array}{c}0,166 \mathrm{~ns} \\
(0,383)\end{array}$ & $\begin{array}{c}0,179 \mathrm{~ns} \\
(0,401)\end{array}$ & $\begin{array}{l}0,155 \mathrm{~ns} \\
(0,401)\end{array}$ \\
\hline Género: mujer & $\begin{array}{l}-0,453^{\star \star} \\
(0,148)\end{array}$ & $\begin{array}{l}-0,456 \text { ** } \\
(0,149)\end{array}$ & $\begin{array}{l}-0,431^{\star \star} \\
(0,15)\end{array}$ & $\begin{array}{l}-0,433^{\star \star} \\
(0,151)\end{array}$ & $\begin{array}{l}-0,419^{\star \star} \\
(0,150)\end{array}$ & $\begin{array}{l}-0,420^{\star *} \\
(0,151)\end{array}$ \\
\hline Constante & $\begin{array}{l}-1,731^{* * *} \\
(0,390)\end{array}$ & $\begin{array}{l}-2,084^{\star \star \star} \\
(0,410)\end{array}$ & $\begin{array}{l}-2,137^{\star \star *} \\
(0,415)\end{array}$ & $\begin{array}{l}-2,029^{* \star *} \\
(0,408)\end{array}$ & $\begin{array}{l}-1,991 * * * \\
(0,411)\end{array}$ & $\begin{array}{l}-2,065^{\star \star \star} \\
(0,415)\end{array}$ \\
\hline $\begin{array}{l}\text { Pseudo- } R^{2} \text { Nacielkerke } \\
N^{0} \text { de casos }\end{array}$ & $\begin{array}{c}0.09 \\
1.127\end{array}$ & $\begin{array}{c}0.10 \\
1.115\end{array}$ & $\begin{array}{c}0.11 \\
1.104\end{array}$ & $\begin{array}{c}0.11 \\
1.109\end{array}$ & $\begin{array}{c}0.11 \\
1.109\end{array}$ & $\begin{array}{c}0.11 \\
1.109\end{array}$ \\
\hline
\end{tabular}

Fuente: Cálculos propios a partir de la base Argentina 2015 de Latinobarómetro. Las entradas son coeficientes de regresión logistica. Errores estándar entre paréntesis. Variable dependiente: Confianza Interpersonal (indicador estándar). Variables independientes: ver definición en la Tabla del Anexo ${ }^{* \star *} p<0.001 ;{ }^{* \star} p<0.01$; ${ }^{*} p<0,05 ; \dagger p<0.1 ;$ ns: no significativo

Figura 12 
José Eduardo Jorge, Gabriel Alberto Lamanna, Mara Leguizamón y Ulises Steciow Dejando atrás el discurso de la «grieta». ¿Cómo aumentar la confianza entre los argentinos?

\begin{tabular}{|c|c|c|c|c|}
\hline \multicolumn{5}{|c|}{$\begin{array}{r}\text { Determinantes de la Confianza Generalizada: } \\
\text { Análisis de regresión logística }\end{array}$} \\
\hline & Modelo 1 & Modelo 2 & Modelo 3 & Modelo 4 \\
\hline \multicolumn{5}{|l|}{ Valores } \\
\hline $\begin{array}{l}\text { Valores de Autoexpresión } \\
\text { (Inglehart y Welzel, 2005) }\end{array}$ & $\begin{array}{r}1,856^{*} \\
(0,848)\end{array}$ & $\begin{array}{l}1,835^{*} \\
(0,852)\end{array}$ & & \\
\hline $\begin{array}{l}\text { Valores de Emancipación } \\
\text { (Welzel, 2013) }\end{array}$ & & & $\begin{array}{l}1,191 \mathrm{~ns} \\
(0,872)\end{array}$ & \\
\hline \multicolumn{5}{|l|}{ Desarrollo Humano } \\
\hline $\begin{array}{l}\text { Empoderamiento } \\
\text { (Welzel y Delhey, 2015) }\end{array}$ & & & & $\begin{array}{c}1,335 \mathrm{~ns} \\
(0,864)\end{array}$ \\
\hline \multicolumn{5}{|l|}{ Dimensión Institucional } \\
\hline $\begin{array}{l}\text { Confianza en las institu- } \\
\text { ciones de gobierno }\end{array}$ & $\begin{array}{l}1,580^{* *} \\
(0,611)\end{array}$ & & $\begin{array}{l}1,537^{* *} \\
(0,615)\end{array}$ & $\begin{array}{r}2,212^{* * *} \\
(0,554)\end{array}$ \\
\hline $\begin{array}{l}\text { Confianza en las institu- } \\
\text { ciones politicas }\end{array}$ & & $\begin{array}{r}1,201^{*} \\
(0,612)\end{array}$ & & \\
\hline $\begin{array}{l}\text { Confianza en la Justicia } \\
\text { y la policia }\end{array}$ & & $\begin{array}{c}0,485 \mathrm{~ns} \\
(0,610)\end{array}$ & & \\
\hline $\begin{array}{l}\text { Respeto percibido } \\
\text { por los DDHH }\end{array}$ & $\begin{array}{r}0,929^{*} \\
(0,432)\end{array}$ & $\begin{array}{r}0,873 * \\
(0,435)\end{array}$ & $\begin{array}{c}0,992^{*} \\
(0,434)\end{array}$ & $\begin{array}{c}1,061^{* *} \\
(0,403)\end{array}$ \\
\hline \multicolumn{5}{|l|}{ Comunidad } \\
\hline $\begin{array}{l}\text { Inseguridad del barrio: } \\
\text { robos frecuentes }\end{array}$ & $\begin{array}{l}-1,208 * * \\
(0,394)\end{array}$ & $\begin{array}{l}-1,246^{* *} \\
(0,394)\end{array}$ & $\begin{array}{l}-1,238^{* *} \\
(0,399)\end{array}$ & $\begin{array}{l}-1,263 \cdots * \\
(0,369)\end{array}$ \\
\hline $\begin{array}{l}\text { Bienestar Individual } \\
\text { Satisfacción con las } \\
\text { finanzas del hogar }\end{array}$ & $\begin{array}{l}1,880 * * \\
(0,673)\end{array}$ & $\begin{array}{r}1,887^{* *} \\
(0,677)\end{array}$ & $\begin{array}{l}1,747^{* \star} \\
(0,671)^{-}\end{array}$ & $\begin{array}{l}2,082^{* * x} \\
(0,640)\end{array}$ \\
\hline \multicolumn{5}{|l|}{ Participación Social } \\
\hline Asociacionismo voluntario & $\begin{array}{l}-1,728 \dagger \\
(0,901)\end{array}$ & $\begin{array}{l}-1,764 * \\
(0,906)\end{array}$ & $\begin{array}{l}-1,976 * \\
(0,949)\end{array}$ & $\begin{array}{l}-1,722 * \\
(0,869)\end{array}$ \\
\hline Importancia de los amigos & $\begin{array}{l}1,905^{* *} \\
(0,608)\end{array}$ & $\begin{array}{r}1,967^{* * *} \\
(0,610)\end{array}$ & $\begin{array}{l}1,836^{* *} \\
(0,606)\end{array}$ & $\begin{array}{c}1,691 * * \\
(0,554)\end{array}$ \\
\hline $\begin{array}{l}\text { Actividad en movimientos } \\
\text { sociales }\end{array}$ & & & $\begin{array}{l}0,454 \mathrm{~ns} \\
(0,494)\end{array}$ & \\
\hline $\begin{array}{l}\text { Personalidad } \\
\text { Religiosidad }\end{array}$ & $\begin{array}{l}-1,611^{x * *} \\
(0,496)\end{array}$ & $\begin{array}{l}-1,669^{* * *} \\
(0,505)\end{array}$ & $\begin{array}{l}-1,634^{* \times *} \\
(0,497)\end{array}$ & $\begin{array}{l}-1,670^{* * x} \\
(0,458)\end{array}$ \\
\hline $\begin{array}{l}\text { Sentimiento de libertad } \\
\text { y control }\end{array}$ & $\begin{array}{c}1,143 \dagger \\
(0,707)\end{array}$ & $\begin{array}{l}1,143 \dagger \\
(0,705)\end{array}$ & $\begin{array}{l}1,035 \mathrm{~ns} \\
(0,699)\end{array}$ & $\begin{array}{r}1,006 \mathrm{~ns} \\
(0,643)\end{array}$ \\
\hline $\begin{array}{l}\text { Movilización Cognoscitiva } \\
\text { Nivel educativo }\end{array}$ & $\begin{array}{l}-0,566 \mathrm{~ns} \\
(0,457)\end{array}$ & $\begin{array}{l}-0,551 \mathrm{~ns} \\
(0,459)\end{array}$ & $\begin{array}{l}-0,573 \mathrm{~ns} \\
(0,461)\end{array}$ & \\
\hline Trabajo estimulante & $\begin{array}{l}1,340^{* *} \\
(0,499)\end{array}$ & $\begin{array}{l}1,324^{* *} \\
(0,500)\end{array}$ & $\begin{array}{l}1,345^{* *} \\
(0,504)\end{array}$ & \\
\hline Variables Demográficas & & & & \\
\hline $\begin{array}{l}\text { Nivel de ingreso familiar } \\
\text { (en deciles) }\end{array}$ & $\begin{array}{l}-2,842^{* * *} \\
(0,809)\end{array}$ & $\begin{array}{l}-2,906^{* * *} \\
(0,815)\end{array}$ & $\begin{array}{l}-2,978^{* * *} \\
(0,816)\end{array}$ & $\begin{array}{l}-2,129 * * \\
(0,721)\end{array}$ \\
\hline Edad & $\begin{array}{r}0,731 \mathrm{~ns} \\
(0,641)\end{array}$ & $\begin{array}{c}0,766 \mathrm{~ns} \\
(0,646)\end{array}$ & $\begin{array}{l}0,539 \mathrm{~ns} \\
(0,648)\end{array}$ & $\begin{array}{c}0,886 \dagger \\
(0,554)\end{array}$ \\
\hline Género: mujer & $\begin{array}{r}0,192 \text { ns } \\
(0,245)\end{array}$ & $\begin{array}{r}0,229 \mathrm{~ns} \\
(0,246)\end{array}$ & $\begin{array}{l}0,118 \mathrm{~ns} \\
(0,248)\end{array}$ & $\begin{array}{c}0,282 \mathrm{~ns} \\
(0,227)\end{array}$ \\
\hline Constante & $\begin{array}{r}-5,054 \\
(0,965)\end{array}$ & $\begin{array}{c}-5,065 * \cdots \\
(0,967)\end{array}$ & $\begin{array}{c}-4,556^{* * *} \\
(1,002)\end{array}$ & $\begin{array}{l}-5,128 \cdots * \\
(0,875)\end{array}$ \\
\hline Pseudo $\mathbf{R}^{2}$ Nage & 0,24 & 0,25 & 0,23 & 0,22 \\
\hline $\mathrm{N}^{\circ}$ de casos & 782 & 777 & 764 & 865 \\
\hline
\end{tabular}

Fuente: Cálculos propios a partir de la base Argentina 2013 de la WVS. Las entradas son coeficientes de regresión logistica. Errores estándar entre parén-tesis. Variable dependiente: Confianza Generalizada: tipologia (Jorge, 2016a). Variables independientes: ver definición en Tabla del Anexo ${ }^{* * *} p<0.001 ;{ }^{* *} p<0.01 ;{ }^{*} p<0,05 ; \uparrow p<0.1 ;$ ns:no significativo

Figura 13 
José Eduardo Jorge, Gabriel Alberto Lamanna, Mara Leguizamón y Ulises Steciow Dejando atrás el discurso de la «grieta». ¿Cómo aumentar la confianza entre los argentinos?

Determinantes de la Confianza en el Exogrupo: Argentina 2013

Análisis de regresión lineal

\begin{tabular}{|c|c|c|c|c|}
\hline \multicolumn{5}{|c|}{ Análisis de regresión lineal } \\
\hline & Modelo 1 & Modelo 2 & Modelo 3 & Modelo 4 \\
\hline Confianza en el endogrupo & $\begin{array}{r}0,686^{* * *} \\
(15,073)\end{array}$ & $\begin{array}{r}0,675^{* * *} \\
(14,929)^{*}\end{array}$ & $\begin{array}{r}0,704^{* * *} \\
(15,125)\end{array}$ & $\begin{array}{r}0,700^{* * *} \\
(15,988)\end{array}$ \\
\hline $\begin{array}{l}\text { Valores } \\
\text { Valores de Autoexpresión } \\
\text { (Inglehart y Welzel, 2005) }\end{array}$ & $\begin{array}{l}0,160^{* *} \\
(2,911)\end{array}$ & $\begin{array}{l}0,156^{* *} \\
(2,843)\end{array}$ & & \\
\hline $\begin{array}{l}\text { Valores de Emancipación } \\
\text { (Welzel, 2013) }\end{array}$ & & & $\begin{array}{l}0,095 \uparrow \\
(1,714)\end{array}$ & \\
\hline $\begin{array}{l}\text { Desarrollo Humano } \\
\text { Empoderamiento } \\
\text { (Welzel y Delhey, 2015) }\end{array}$ & & & & $\begin{array}{l}0,193^{* * *} \\
(3,542)\end{array}$ \\
\hline Dimensión Institucional & & & & \\
\hline $\begin{array}{l}\text { Confianza en las institu- } \\
\text { ciones de gobierno }\end{array}$ & & $\begin{array}{l}0,156^{* * \star} \\
(4,060)\end{array}$ & & \\
\hline $\begin{array}{l}\text { Confianza en las institu- } \\
\text { ciones politicas }\end{array}$ & $\begin{array}{l}0,073 \uparrow \\
(1,897)\end{array}$ & & $\begin{array}{l}0,058 \mathrm{~ns} \\
(1,487)\end{array}$ & $\begin{array}{c}0,090^{* *} \\
(2,480)\end{array}$ \\
\hline $\begin{array}{l}\text { Confianza en la Justicia } \\
\text { y la policia }\end{array}$ & $\begin{array}{l}0,078^{*} \\
(2,160)\end{array}$ & & $\begin{array}{l}0,070 \dagger \\
(1,920)\end{array}$ & $\begin{array}{c}0,089^{* *} \\
(2,590)\end{array}$ \\
\hline $\begin{array}{l}\text { Respeto percibido } \\
\text { por los } \mathrm{DDHH}\end{array}$ & $\begin{array}{l}0,080^{* \star} \\
(3,047)\end{array}$ & $\begin{array}{l}0,077^{\star \star} \\
(2,952)\end{array}$ & $\begin{array}{l}0,074^{\star \star} \\
(2,780)\end{array}$ & $\begin{array}{r}0,085^{* * *} \\
(3,399)\end{array}$ \\
\hline Comunidad & & & & \\
\hline $\begin{array}{l}\text { Intolerancia etnica y } \\
\text { religiosa }\end{array}$ & $\begin{array}{l}-0,043 \dagger \\
(-1,799)\end{array}$ & $\begin{array}{l}-0,045+ \\
(-1,903)\end{array}$ & $\begin{array}{l}-0,044+ \\
(-1,827)\end{array}$ & $\begin{array}{l}-0,056 * \\
(-2,418)\end{array}$ \\
\hline $\begin{array}{l}\text { Bienestar Individual } \\
\text { Satisfacción con las } \\
\text { finanzas del hogar }\end{array}$ & $\begin{array}{r}-0,077^{\star} \\
(-2,017)\end{array}$ & $\begin{array}{l}-0,073^{*} \\
(-1,925)\end{array}$ & $\begin{array}{l}-0,073 \uparrow \\
(-1,870)\end{array}$ & $\begin{array}{l}-0,043 \mathrm{~ns} \\
(-1,168)\end{array}$ \\
\hline Participación Social & & & & \\
\hline $\begin{array}{l}\text { Actividad en movimientos } \\
\text { sociales }\end{array}$ & & & $\begin{array}{l}-0,014 \mathrm{~ns} \\
(-0,432)\end{array}$ & \\
\hline Personalidad & & & & \\
\hline Religiosidad & $\begin{array}{l}-0,048+ \\
(-1,607)\end{array}$ & $\begin{array}{l}-0,051 \dagger \\
(-1,711)\end{array}$ & $\begin{array}{l}-0,045 \mathrm{~ns} \\
(-1,496)\end{array}$ & $\begin{array}{l}-0,053 \dagger \\
(-1,862)\end{array}$ \\
\hline $\begin{array}{l}\text { Movilización Cognoscitiva } \\
\text { Nivel educativo }\end{array}$ & $\begin{array}{l}0,014 \mathrm{~ns} \\
(0,525)\end{array}$ & $\begin{array}{l}0,014 \mathrm{~ns} \\
(0,520)\end{array}$ & $\begin{array}{l}0,023 \mathrm{~ns} \\
(0,810)\end{array}$ & \\
\hline Trabajo estimulante & $\begin{array}{l}0,100^{* * *} \\
(3,441)\end{array}$ & $\begin{array}{l}0,098^{* * *} \\
(3,375)\end{array}$ & $\begin{array}{l}0,108^{* * *} \\
(3,676)\end{array}$ & \\
\hline $\begin{array}{l}\text { Variables Demográficas } \\
\text { Nivel de ingreso familiar } \\
\text { (en deciles) }\end{array}$ & $\begin{array}{l}-0,106^{*} \\
(-2,236)\end{array}$ & $\begin{array}{l}-0,105 * \\
(-2,226)\end{array}$ & $\begin{array}{l}-0,115 * \\
(-2,392)\end{array}$ & $\begin{array}{r}-0,094^{*} \\
(-2,119)\end{array}$ \\
\hline Edad & $\begin{array}{l}0,039 \mathrm{~ns} \\
(1,031)\end{array}$ & $\begin{array}{l}0,045 \mathrm{~ns} \\
(1,196)\end{array}$ & $\begin{array}{c}0,033 \mathrm{~ns} \\
(0,863)\end{array}$ & $\begin{array}{c}0,048 \mathrm{~ns} \\
(1,392)\end{array}$ \\
\hline Género: mujer & $\begin{array}{l}0,003 \mathrm{~ns} \\
(0,218)\end{array}$ & $\begin{array}{r}0,001 \mathrm{~ns} \\
(0,066)\end{array}$ & $\begin{array}{l}-0,005 \mathrm{~ns} \\
(-0,325)\end{array}$ & $\begin{array}{c}0,009 \mathrm{~ns} \\
(0,675)\end{array}$ \\
\hline Constante & $\begin{array}{l}-0,146^{* *} \\
(-2,805)\end{array}$ & $\begin{array}{l}-0,139 * * \\
(-2,672)\end{array}$ & $\begin{array}{c}-0,129 \\
(-2,329)\end{array}$ & $\begin{array}{r}-0,167 \\
(-3,378)\end{array}$ \\
\hline$R^{2}$ ajustada & 0,30 & 0,30 & 0,30 & 0,30 \\
\hline $\mathrm{N}^{\circ}$ de casos & 783 & 789 & 782 & 871 \\
\hline
\end{tabular}

Fuente: Cálculos propios a partir de la base Argentina 2013 de la WVS. Las entradas son coeficientes de regresión no tipificados. Valores t entre paréntesis. Variable dependiente Confianza en el Exogrupo. Variables independientes: ver definición en Tabla del Anexo *** $p<0.001 ; * * 0<0.01 ;{ }^{*} p<0,05 ; \dagger p<0.1 ;$ ns: no significativo

Figura 14 
José Eduardo Jorge, Gabriel Alberto Lamanna, Mara Leguizamón y Ulises Steciow Dejando atrás el discurso de la «grieta». ¿Cómo aumentar la confianza entre los argentinos?

Determinantes de la Confianza en el Endogrupo: Argentina 2013

Análisis de regresión lineal

\begin{tabular}{|c|c|c|c|c|}
\hline & ISIS de regre & esion lineal & & \\
\hline \multirow{2}{*}{\multicolumn{5}{|c|}{ Valores }} \\
\hline & & & & \\
\hline $\begin{array}{l}\text { Valores de Autoexpresión } \\
\text { (Inglehart y Welzel, 2005) }\end{array}$ & & $\begin{array}{l}0,118^{* *} \\
(3,179)\end{array}$ & & \\
\hline $\begin{array}{l}\text { Valores de Emancipación } \\
\text { (Welzel, 2013) }\end{array}$ & $\begin{array}{l}0,127^{\star \star \star} \\
(3,439)\end{array}$ & & $\begin{array}{l}0,129^{\star * *} \\
(3,496)\end{array}$ & \\
\hline \multicolumn{5}{|l|}{ Desarrollo Humano } \\
\hline $\begin{array}{l}\text { Empoderamiento } \\
\text { (Welzel y Delhey, 2015) }\end{array}$ & & & & $\begin{array}{l}-0,015 \mathrm{~ns} \\
(-0,365)\end{array}$ \\
\hline $\begin{array}{l}\text { Dimensión Institucional } \\
\text { Confianza en las institu- } \\
\text { ciones politicas }\end{array}$ & $\begin{array}{l}0,043 \text { * } \\
(1,978)\end{array}$ & $\begin{array}{l}0,043 \text { * } \\
(2,006)\end{array}$ & $\begin{array}{r}0,037 \dagger \\
(1,609)\end{array}$ & $\begin{array}{l}0,048 \text { * } \\
(2,212)\end{array}$ \\
\hline Confianza en la Policia & & & $\begin{array}{l}0,021 \mathrm{~ns} \\
(1,085)\end{array}$ & \\
\hline $\begin{array}{l}\text { Comunidad } \\
\text { Tamaño de la localidad }\end{array}$ & $\begin{array}{l}-0,060^{* \pi *} \\
(-4,094)\end{array}$ & $\begin{array}{l}-0,060^{* * *} \\
(-4,023)\end{array}$ & $\begin{array}{l}-0,056^{* * *} \\
(-3,781)^{*}\end{array}$ & $\begin{array}{l}-0,054^{* * *} \\
(-3,649)\end{array}$ \\
\hline $\begin{array}{l}\text { Intolerancia étnica y } \\
\text { religiosa }\end{array}$ & $\begin{array}{l}-0,032 * \\
(-1,936)\end{array}$ & $\begin{array}{l}-0,032 \dagger \\
(-1,915)\end{array}$ & $\begin{array}{l}-0,0366^{*} \\
(-2,155)\end{array}$ & $\begin{array}{l}-0,037^{\star} \\
(-2,192)\end{array}$ \\
\hline $\begin{array}{l}\text { Bienestar Individual } \\
\text { Satisfacción con la vida }\end{array}$ & $\begin{array}{l}0,081 \approx * \\
(2,709)\end{array}$ & $\begin{array}{l}0,090^{* \star} \\
(3,025)\end{array}$ & $\begin{array}{l}0,083^{\star *} \\
(2,794)\end{array}$ & $\begin{array}{l}0,094^{* \star} \\
(3,164)\end{array}$ \\
\hline \multicolumn{5}{|l|}{ Personalidad } \\
\hline Importancia de los amigos & $\begin{array}{l}0,162 \times \approx \pi \\
(7,839)\end{array}$ & $\begin{array}{l}0,159 \times \approx \times \\
(7,712)\end{array}$ & $\begin{array}{l}0,163^{\star * \star} \\
(7,907)\end{array}$ & $\begin{array}{l}0,160 \times * \star \\
(7,702)\end{array}$ \\
\hline $\begin{array}{l}\text { Amigos y colegas como } \\
\text { fuentes de información }\end{array}$ & $\begin{array}{l}0,054^{\star \star} \\
(3,030)\end{array}$ & $\begin{array}{l}0,054^{\star \star} \\
(3,013)\end{array}$ & $\begin{array}{l}0,054^{\star \star} \\
(3,044)\end{array}$ & $\begin{array}{l}0,060^{* \star *} \\
(3,228)\end{array}$ \\
\hline \multicolumn{5}{|l|}{ Rasgos Individuales } \\
\hline $\begin{array}{l}\text { Sentimiento de libertad } \\
\text { y control }\end{array}$ & $\begin{array}{l}0,055^{*} \\
(1,943)\end{array}$ & $\begin{array}{r}0,052 \dagger \\
(1,843)\end{array}$ & $\begin{array}{l}0,055^{*} \\
(1,934)\end{array}$ & $\begin{array}{l}0,057 \text { * } \\
(2,017)\end{array}$ \\
\hline $\begin{array}{l}\text { Variables Demográficas } \\
\text { Nivel educativo }\end{array}$ & $\begin{array}{l}-0,032 \dagger \\
(-1,667)\end{array}$ & $\begin{array}{l}-0,035 \dagger \\
(-1,823)\end{array}$ & $\begin{array}{l}-0,032 \dagger \\
(-1,667)\end{array}$ & \\
\hline $\begin{array}{l}\text { Nivel de ingreso familiar } \\
\text { (en deciles) }\end{array}$ & $\begin{array}{l}-0,034 \text { ns } \\
(-1,112)\end{array}$ & $\begin{array}{c}-0,038 \mathrm{~ns} \\
(-1,235)\end{array}$ & $\begin{array}{c}-0,037 \mathrm{~ns} \\
(-1,214)\end{array}$ & $\begin{array}{l}-0,039 \mathrm{~ns} \\
(-1,239)\end{array}$ \\
\hline Edad & $\begin{array}{c}0,039 \mathrm{~ns} \\
(1,519)\end{array}$ & $\begin{array}{c}0,038 \mathrm{~ns} \\
(1,506)\end{array}$ & $\begin{array}{l}0,036 \mathrm{~ns} \\
(1,417)\end{array}$ & $\begin{array}{c}0,042 \dagger \\
(1,704)\end{array}$ \\
\hline Género: mujer & $\begin{array}{c}-0,013 \text { ns } \\
(-1,339)\end{array}$ & $\begin{array}{l}-0,011 \mathrm{~ns} \\
(-1,098)\end{array}$ & $\begin{array}{l}-0,014 \mathrm{~ns} \\
(-1,388)\end{array}$ & $\begin{array}{l}-0,009 \mathrm{~ns} \\
(-0,943)\end{array}$ \\
\hline Constante & $\begin{array}{c}0,484^{* \star \star *} \\
(12,817)\end{array}$ & $\begin{array}{c}0,500^{\star \star \star *} \\
(13,682)\end{array}$ & $\begin{array}{r}0,474^{* * *} \\
(12,342)\end{array}$ & $\begin{array}{c}0,519 \\
(14,381)\end{array}$ \\
\hline $\mathbf{R}^{2}$ ajustada & 0,14 & 0,14 & 0,14 & 0,13 \\
\hline $\mathrm{N}^{\circ}$ de casos & & & 917 & 920 \\
\hline
\end{tabular}

Fuente: Cálculos propios a partir de la base Argentina 2013 de la WVS. Las entradas son coeficientes de regresión no tipificados. Valores t entre paréntesis. Variable dependiente: Confianza en el Exogrupo. Variables independientes: ver definición en Tabla del Anexo. ${ }^{* * x} p<0.001 ;{ }^{* \approx} p<0.01 ;{ }^{*} p<0,05 ; \dagger p<0.1 ; n s$ : no significativo

Figura 15 
José Eduardo Jorge, Gabriel Alberto Lamanna, Mara Leguizamón y Ulises Steciow Dejando atrás el discurso de la «grieta». ¿Cómo aumentar la confianza entre los argentinos?

\section{Referencias bibliográficas}

Armingeon, K. \& Guthmann, K. (2014). Democracy in Crisis? The declining support for national democracy in European countries 2007-2011. European Journal of Political Research, $53,423-42$.

Bjørnskov, C. y Svendsen, G. T. (2013). Does social trust determine the size of the welfare state? Evidence using historical identification. Public Choice, 157, 269- 86.

Bosco, A. y Verney, S. (2012). Electoral Epidemic: The Political Cost of Economic Crisis in Southern Europe, 2010-11. South European Society and Politics, 17(2), 129-54.

Carlin, R. E. y Love, G. J. (2016). Political Competition, Partisanship and Interpersonal Trust in Electoral Democracies. British Journal of Political Science, 48, 115-139.

Delhey, J. y Newton, K. (2003). Who Trusts? The Origins of Social Trust in Seven Societies. European Societies, 5(2), 93-137.

Delhey, J. y Newton, K. (2005). Predicting Cross-National Levels of Social Trust: Global Pattern or Nordic Exceptionalism? European Sociological Review, 21(4), 311-327.

Delhey, J. Newton, K. y Welzel, C. (2011). How General is Trust in "Most People"? Solving the Radius of Trust Problem. American Sociological Review, 76(5), 786-807.

Delhey, J. y Welzel, C. (2012). Generalizing Trust: What Extends Trust from Ingroups to Outgroups? World Values Research, 5(3), 45-69.

Easton, D. (1965). A Framework for Political Analysis. Englewood Cliffs: Prentice-Hall.

Freitag, M., y Buhlmann, M. (2009). Crafting trust: The role of political institutions in a comparative perspective. Comparative Political Studies, 42(12), 1537-66.

Fiorina, M.P. y Abrams, S.J. (2008). Political Polarization in the American Public. Annual Review of Political Science, 11, 563-568.

Gertz, G. y Kharas, H. (eds.) (2019). Beyond Neoliberalism. Insights from Emerging Markets. Washington: Brookings Institution.

Glanville, J. L., Andersson, M. A. y Paxton, P. (2013). Do social connections create trust? An examination using new longitudinal data. Social Forces, 92(2), 545-62.

Haselmayer, M. (2019). Negative campaigning and its consequences: a review and a look ahead. French Politics,17(3), 355-72.

Huber, E. y Stephens, J. D. (2012). Democracy and the Left. Social Policy and Inequality in Latin America. Chicago: The University of Chicago Press.

Inglehart, R. F. y Welzel, C. (2005). Modernization, Cultural Change, and Democracy. Cambridge: Cambridge University Press.

Inglehart, R. (2016). Inequality and Modernization. Foreign Affairs, 95(1): 2-10. 
Inglehart, R. F. (1999). Trust, well-being and democracy. En Warren, M. (ed.) (pp. 88-120), op. cit

Jorge, J. E. (2018a). Ni "grieta" ni "degradación moral": un contraste empírico del relato político en Argentina. Question, 1(59), 1-33.

Jorge, J.E. (2018b). Valores Democráticos para Tiempos de Crisis. Hallazgos de dos Teorías. Question, 1(57), 1-33.

Jorge, J.E. (2017). Estado de Derecho y Valores Democráticos. Las Direcciones del Cambio Cultural. Question, 1(54), 172-206.

Jorge, J.E. (2016a). La Confianza Interpersonal Revela sus Misterios. ¿La Partícula de Dios? Question, 1(52), 143-74.

Jorge, J.E. (2016b). Teoría de la Cultura Política. Enfocando el Caso Argentino. Question, 1(49): 300-21.

Jorge, J.E. (2015). La Cultura Política Argentina: una Radiografía. Question, 1(48): 372-403.

Jorge, J.E. (2010). Cultura Política y Democracia en Argentina. La Plata: Edulp.

Kuttner, R. (2018). Can Democracy Survive Global Capitalism? New York: W. W. Norton \& Company.

Levendusky, M. (2009). The Partisan Sort. Chicago: The University of Chicago Press.

Levendusky, M. y Malhotra, N. (2016). Does Media Coverage of Partisan Polarization Affect Political Attitudes? Political Communication, 33(2), 283-301,

Lewis-Beck, M. S. y Costa Lobo, M. (2017). The Economic Vote: Ordinary vs. Extraordinary Times. En Arzheimer, K., Evans, J. y Lewis-Beck, M. S. (eds.) (pp. 606-29). The SAGE Handbook of Electoral Behaviour. Thousand Oaks: SAGE.

Listhaug, L. y Jakobsen, T. G. (2018). Foundations of Political Trust. En Uslaner, E. M. (ed.) (pp. 559-77), op. cit.

Liu, C. y Stolle, D. (2017). Social capital, civic culture and political trust. En Zmerli, S. y Van der Meer, T. W. G. (pp. 338-52), op. cit.

Mason, L. (2015). "I Disrespectfully Agree": The Differential Effects of Partisan Sorting on Social and Issue Polarization. American Journal of Political Science, 59(1), 128-145

Mounk, Y. (2018). The People vs. Democracy. Cambridge: Harvard University Press.

Nannestad, P. (2008). What have we learned about generalized trust, if anything? Annual Review of Political Science, 11(1), 413-436.

Newton, K., Stolle, D. y Zmerli, S. (2018). Social and Political Trust. En Uslaner, E. (ed.) (pp. 37-56), op. cit.

Newton, K. y Zmerli, S. (2011). Three forms of trust and their association. European Political Science Review, 3(02), 169-200.

Question, Vol. 1, N. ${ }^{\circ} 65$, abril 2020. ISSN 1669-6581

Instituto de Investigaciones en Comunicación | Facultad de Periodismo y Comunicación Social | Universidad Nacional de La Plata La Plata | Buenos Aires | Argentina

Página 29 de 33 
Newton, K. y Norris, P. (2000). Confidence in public institutions. Faith, culture, or performance? En Pharr, S. J. y Putnam, R. D. (eds) (pp. 52-73). Disaffected Democracies. What's Troubling the Trilateral Countries? Princeton: Princeton University Press.

Newton, K. (1999). Social and Political Trust in Established Democracies. En Norris, P. (ed.) (pp. 169-87). Critical Citizens. New York: Oxford University Press.

Norris, P. (2011). Democratic Deficit. Critical Citizens Revisited. New York: Cambridge University Press.

Putnam, R. D. (2000). Bowling Alone. New York: Simon \& Schuster.

Putnam, R. D. (1993). Making Democracy Work. Princeton: Princeton University Press.

Reich, R. B. (2015). Saving Capitalism: For the Many, not the Few. New York: Knopf.

Rodrik, D. (2018). Globalisation: New Deal On Labour Mobility. Social Europe, 26 de abril. Recuperado de http://www.socialeurope.eu

Rodrik, D. (2011). The Globalization Paradox. Oxford: Oxford University Press.

Rothstein, B. (2015). The Chinese Paradox of High Growth and Low Quality of Government: The Cadre Organization Meets Max Weber. Governance, 28, 533-548.

Rothstein, B. (2010). Corruption, Happiness, Social Trust and the Welfare State: A Causal Mechanisms Approach. Working Paper № 9. Göteborg: The Quality of Government Institute.

Rothstein, B. y Stolle, D. (2008). The state and social capital: An institutional theory of generalized trust. Comparative Politics, 40, 441-459.

Tang, W. (2016). Populist Authoritarianism. Chinese Political Culture and Regime Sustainability. New York: Oxford University Press.

Uslaner, E. M. (ed.) (2018). The Oxford Handbook of Social and Political Trust. New York: Oxford University Press.

Uslaner, E. M. (2008). Corruption, Inequality, and the Rule of Law. New York: Cambridge University Press.

Uslaner, E. M. (2002). The Moral Foundations of Trust. New York: Cambridge University Press.

Warren, M. (ed.) (1999). Democracy and Trust. Cambridge: Cambridge University Press.

Welch, M. R., Rivera, R. E., Conway, B. P., Yonkoski, J., Lupton, P. M. y Giancola, R. (2005). Determinants and Consequences of Social Trust. Sociological Inquiry, 75(4), 453-473.

Welzel, C., y Delhey, J. (2015). Generalizing Trust: The Benign Force of Emancipation. Journal of Cross-Cultural Psychology, 46, 1-22.

Welzel, C. (2014). Evolution, empowerment and emancipation: How societies climb the freedom ladder. World Development, 64, 33-51.

Welzel, C. (2013). Freedom Rising. New York: Cambridge University Press. 
Zmerli, S. y Van der Meer, T. W.G. (eds.) (2017). Handbook on Political Trust. Cheltenham, UK: Edward Elgar.

Zmerli, S. y Newton, K. (2008). Social Trust and Attitudes Toward Democracy. Public Opinion Quarterly, 72 (4), 706-724.

Zmerli, S. y Castillo, J. C. (2015). Income inequality, distributive fairness and political trust in Latin America. Social Science Research, 52, 179-192.

Anexo 
José Eduardo Jorge, Gabriel Alberto Lamanna, Mara Leguizamón y Ulises Steciow Dejando atrás el discurso de la «grieta». ¿Cómo aumentar la confianza entre los argentinos?

Tabla - Variables utilizadas en los análisis de regresión

\begin{tabular}{|c|c|c|c|}
\hline $\begin{array}{l}\text { Variable (I: Índice de dos o más } \\
\text { items) }\end{array}$ & $\begin{array}{c}\text { Descripción e ítems de la } \\
\text { variable }\end{array}$ & $\begin{array}{c}\text { Preguntas en } \\
\text { WVS }\end{array}$ & $\begin{array}{c}\text { Escala y } \mathbf{n}^{\circ} \text { de } \\
\text { valores de cada } \\
\text { item en WVS }\end{array}$ \\
\hline $\begin{array}{l}\text { Confianza estándar: en "la } \\
\text { mayoria de la gente" }\end{array}$ & Pregunta única & A165 & Dicotómica \\
\hline Confianza en el endogrupo (I) & $\begin{array}{l}\text { Confianza en la familia, el } \\
\text { vecindario y gente que conoce } \\
\text { personalmente (promedio) }\end{array}$ & $\begin{array}{l}\text { D001_B, } \\
\text { G007_18_B, } \\
\text { G007_33_B }\end{array}$ & Ordinal (4 valores) \\
\hline Confianza en el exogrupo (I) & $\begin{array}{l}\text { Confianza en gente de otra } \\
\text { religión o nacionalidad o que ve } \\
\text { por primera vez }\end{array}$ & $\begin{array}{l}\text { G007_34_B, } \\
\text { G007_35_B, } \\
\text { G007_36_B }\end{array}$ & Ordinal (4) \\
\hline Confianza generalizada (I) & \multicolumn{3}{|c|}{ Tipología (Jorge, 2016a: 156-8) Dicotomía } \\
\hline $\begin{array}{l}\text { Confianza en las Instituciones de } \\
\text { Gobierno (I) }\end{array}$ & $\begin{array}{l}\text { Congreso, Partidos, Gobierno, } \\
\text { Funcionarios, Justicia y Policia }\end{array}$ & $\begin{array}{l}\text { E069 }(06,07 \\
08,11,12,17)\end{array}$ & \multirow{3}{*}{ Ordinal (4) } \\
\hline \begin{tabular}{|l}
$\begin{array}{l}\text { Confianza en las Instituciones } \\
\text { Politicas (I) }\end{array}$ \\
\end{tabular} & Congreso, Partidos y Gobierno & $\begin{array}{l}\text { E069 }(07,11, \\
12)\end{array}$ & \\
\hline \begin{tabular}{|l} 
Confianza en la Justicia y la \\
Policia (I)
\end{tabular} & Justicia y Policia & E069 $(06,17)$ & \\
\hline Respeto percibido por $\mathrm{DDHH}$ & Pregunta única & E124 & Ordinal (4) \\
\hline Democraticidad del pais & Pregunta única & E236 & Intervalo (10) \\
\hline $\begin{array}{l}\text { Inseguridad del barrio: frecuencia } \\
\text { de robos }\end{array}$ & Pregunta única & H002_01 & Ordinal (4) \\
\hline Tamaño de la localidad & Pregunta única & X049 & Ordinal (8) \\
\hline Intolerancia étnica y religiosa (I) & $\begin{array}{l}\text { Vecinos no deseados: inmigrantes } \\
\text { y personas de otra raza, lengua o } \\
\text { religión, }\end{array}$ & $\begin{array}{l}\text { A124 (02, 06, } \\
12,43)\end{array}$ & Dicotómica \\
\hline Índice de asociacionismo (I) & $\begin{array}{l}\text { Miembro activo o inactivo de } \\
\text { organizaciones voluntarias }\end{array}$ & $\begin{array}{l}\text { De A098 a } \\
\text { A106, A106B }\end{array}$ & Ordinal (3) \\
\hline $\begin{array}{l}\text { Actividad en movimientos } \\
\text { sociales (I) }\end{array}$ & $\begin{array}{l}\text { Firma de petitorios y participación } \\
\text { en manifestaciones y boicots }\end{array}$ & $\begin{array}{l}\text { E025, E026, } \\
\text { E027 }\end{array}$ & Ordinal (3) \\
\hline Importancia de los amigos & Pregunta única & A002 & Ordinal: (4) \\
\hline Religiosidad (I) & $\begin{array}{l}\text { Importancia de la religión, persona } \\
\text { religiosa y frecuencia de } \\
\text { asistencia a misa }\end{array}$ & $\begin{array}{l}\text { A006, F028, } \\
\text { F034 }\end{array}$ & $\begin{array}{l}\text { Ordinales }(4,3 \text { y } 8 \\
\text { respectivamente) }\end{array}$ \\
\hline Sentimiento de libertad y control & Pregunta única & A173 & Intervalo (10) \\
\hline $\begin{array}{l}\text { Satisfacción con las.finanzas del } \\
\text { hogar }\end{array}$ & Pregunta única & $\mathrm{C} 006$ & Intervalo (10) \\
\hline Satisfacción con la vida & Pregunta única & A170 & Intervalo (10) \\
\hline Libertad de elección (I) & $\begin{array}{l}\text { Justificación del aborto, el divorcio } \\
\text { y la homosexualidad }\end{array}$ & $\begin{array}{l}\text { F118, F120, } \\
\text { F121 }\end{array}$ & Intervalo (10) \\
\hline
\end{tabular}


José Eduardo Jorge, Gabriel Alberto Lamanna, Mara Leguizamón y Ulises Steciow Dejando atrás el discurso de la «grieta». ¿Cómo aumentar la confianza entre los argentinos?

Tabla: continuación(1)

\begin{tabular}{|c|c|c|c|}
\hline $\begin{array}{l}\text { Variable (I: Índice de dos o más } \\
\text { items) }\end{array}$ & $\begin{array}{c}\text { Descripción e items de la } \\
\text { variable }\end{array}$ & $\begin{array}{l}\text { Preguntas en } \\
\text { WVS }\end{array}$ & $\begin{array}{c}\text { Escala y } \mathrm{n}^{\circ} \text { de } \\
\text { valores de cada } \\
\text { item en WVS }\end{array}$ \\
\hline $\begin{array}{l}\text { Aspiraciones de libertad (Inglehart } \\
\text { y Welzel, 2005: 239-44) (I) }\end{array}$ & $\begin{array}{l}\text { Prioridad asignada a la libertad de } \\
\text { expresión y a la participación en a) } \\
\text { las decisiones de gobierno y b) el } \\
\text { trabajo y la comunidad }\end{array}$ & $\begin{array}{l}\text { De E001 a } \\
\text { E004 }\end{array}$ & Nominal (4) \\
\hline Igualdad de género (I) & $\begin{array}{l}\text { Desacuerdo con que los hombres } \\
\text { son mejores lideres, tienen priori- } \\
\text { dad para los empleos y necesitan } \\
\text { más una educación superior }\end{array}$ & $\begin{array}{l}\text { C001, D059, } \\
\text { D060 }\end{array}$ & Ordinal $(3,4$ y 4$)$ \\
\hline Valores de autoexpresión (I) & \multicolumn{3}{|l|}{$\begin{array}{l}\text { Promedio: actividad en movi- } \\
\text { mientos sociales, aspiraciones de } \\
\text { libertad, igualdad de género y } \\
\text { libertad de elección }\end{array}$} \\
\hline $\begin{array}{l}\text { Indice de autonomia (Welzel, } \\
\text { 2013, Online Appendix: 20) (I) }\end{array}$ & $\begin{array}{l}\text { Cualidades a enseñar a los niños: } \\
\text { independencia e imaginación, no } \\
\text { obediencia }\end{array}$ & $\begin{array}{l}\mathrm{A} 029, \mathrm{~A} 034, \\
\mathrm{~A} 042\end{array}$ & Dicotómica \\
\hline $\begin{array}{l}\text { Valores de emancipación } \\
\text { (Welzel, 2013, OA: 20-27) (I) }\end{array}$ & $\begin{array}{l}\text { Promedio: autonomia, aspiracio- } \\
\text { nes de libertad, igualdad de } \\
\text { género y libertad de elección }\end{array}$ & $\begin{array}{l}\text { Y020. Compo- } \\
\text { nentes: de } \\
\text { Y021 a Y024 } \\
\end{array}$ & $\begin{array}{l}\text { Intervalo (continua } \\
\text { de } 0 \text { a 1) }\end{array}$ \\
\hline Trabajo estimulante (I) & $\begin{array}{l}\text { Tarea manual vs. cognitiva y } \\
\text { rutinaria vs. creativa }\end{array}$ & $\mathrm{X} 053, \mathrm{X} 054$ & Intervalo (10) \\
\hline $\begin{array}{l}\text { Diversidad de fuentes de } \\
\text { información (I) }\end{array}$ & $\begin{array}{l}\text { Diarios, revistas, TV, radio, email, } \\
\text { Internet,celular, charlas con } \\
\text { amigos y colegas }\end{array}$ & $\begin{array}{l}\text { De E248B a } \\
\text { E262B }\end{array}$ & Dicotómica \\
\hline Nivel de educación & $\begin{array}{l}\text { Pregunta única: máximo nivel } \\
\text { alcanzado }\end{array}$ & X025 & Ordinal (8) \\
\hline $\begin{array}{l}\text { Indice de Empoderamiento } \\
\text { (Welzel y Delhey, 2015) (I) }\end{array}$ & \multicolumn{3}{|l|}{$\begin{array}{l}\text { Promedio: valores de emancipa- } \\
\text { ción, actividad en mov. sociales, } \\
\text { fuentes de información, nivel } \\
\text { educativo y trabajo estimulante }\end{array}$} \\
\hline Ingreso familiar & $\begin{array}{l}\text { Pregunta única: en deciles (auto- } \\
\text { clasificación) }\end{array}$ & X047 & Intervalo (10) \\
\hline
\end{tabular}

